\title{
Biochemical Studies of Stimulus Convergence during Classical Conditioning in Aplysia: Dual Regulation of Adenylate Cyclase by $\mathrm{Ca}^{2+} /$ Calmodulin and Transmitter
}

\author{
Thomas W. Abrams,, ${ }^{1,2}$ Kevin A. Karl,, ${ }^{1}$ and Eric R. Kandel ${ }^{1}$ \\ 'Howard Hughes Medical Institute, Center for Neurobiology and Behavior, Columbia University, College of Physicians and \\ Surgeons, New York, New York 10032 and 'Department of Biology and The Institute of Neurological Sciences, The \\ University of Pennsylvania, Philadelphia, Pennsylvania 19104-6018
}

\begin{abstract}
Activity-dependent facilitation is a mechanism of associative synaptic plasticity that contributes to classical conditioning in Aplysia. Previous studies of activity-dependent facilitation in the mechanosensory neurons of Aplysia suggested that the $\mathrm{Ca}^{2+}$ influx during paired spike activity enhances the transmitter-stimulated, cAMP-dependent, presynaptic facilitation in these cells. Moreover, paired activity was found to potentiate the activation of the adenylate cyclase by transmitter. It was therefore proposed that the $\mathrm{Ca}^{2+} / \mathrm{cal}-$ modulin-sensitive cyclase may serve as a site of interaction between the inputs from the conditioned and unconditioned stimuli. These studies were carried out to test whether a $\mathrm{Ca}^{2+} /$ calmedulin-sensitive adenylate cyclase in the Aplysia CNS has the properties necessary to mediate such an associative interaction.
\end{abstract}

Three lines of evidence indicate that the same cyclase molecules that are sensitive to $\mathrm{Ca}^{2+} /$ calmodulin are also stimulated by receptor to facilitatory transmitter via the stimulatory G-protein, $G_{s}$ : First, calmodulin inhibitors reduced stimulation of the cyclase by facilitatory transmitter. When membranes had been preexposed to one of these inhibitors, trifluoperazine, the addition of exogenous calmodulin partially reversed the inhibition. Second, when $G_{s}$ had been activated by GTP $\gamma S$, so that it persistently activated the catalytic unit of the cyclase, stimulation of the cyclase by $\mathrm{Ca}^{2+}$ was greatly amplified, suggesting that the two inputs interact in activating a common population of the enzyme. Third, solubilized cyclase activity that bound to calmodulin-Sepharose in $\mathrm{C} \mathrm{Ca}^{2+}$-dependent manner was stimulated by $\mathrm{G}_{\mathrm{s}}$, which had been partially purified from Aplysia CNS, as well as by $\mathrm{Ca}^{2+}$ /calmodulin. Having demonstrated dual activation of the cyclase, we have explored the dependence of cyclase activation on the temporal pattern of $\mathrm{Ca}^{2+}$ and transmitter addition. Optimal activation required that a pulse of $\mathrm{Ca}^{2+}$ temporally overlap the addition of facilitatory transmitter.

Received Dec. 14, 1990; revised Mar. 5, 1991; accepted Mar. 22, 1991.

We are grateful to Yoram Yovell and Lise Eliot for their helpful comments on the manuscript and to Yadin Dudai for his thoughtful suggestions throughout this study. We thank John Bilezikian, who generously provided membranes of the S49 $c y c^{-}$lymphoma, and Murray Smigel, whose suggestions aided us in developing the protocol for reconstituting $G_{s}$ with the catalytic unit of the cyclase.

Correspondence should be addressed to Thomas W. Abrams, Department of Biology, The University of Pennsylvania, Philadelphia, PA 19104-6018.

Copyright (c) 1991 Society for Neuroscience 0270-6474/91/112655-11\$03.00/0
These several results suggested that the dually regulated adenylate cyclase might underlie the temporal requirements for effective classical conditioning in this system.

During associative learning, memories are formed and future behavior is altered as a result of an association made between two or more events. Perhaps the simplest form of associative learning is classical conditioning, where the temporal pairing of one event, the conditioned stimulus, with a second event, the unconditioned stimulus, alters the response to the first event. Thus, the animal learns that the conditioned stimulus predicts the unconditioned stimulus (Rescorla, 1988).

Where in the nervous system do the associative interactions between the conditioned and unconditioned stimuli occur during learning? Are these associative interactions an emergent property of complex neural circuits specifically organized for learning, or do they take place among small groups of neurons or perhaps even within individual cells? Recent analysis of mechanisms of learning in Aplysia and Drosophila have suggested that associative changes can result from allosteric interactions at particular molecular loci within single neurons (Dudai and Zvi, 1984; Livingstone et al., 1984; Abrams and Kandel 1985, 1988; Ocorr et al., 1985; Yovell and Dudai, 1987). In classical conditioning of the defensive withdrawal reflex of Aplysia, the convergent regulation of adenylate cyclase by $\mathrm{Ca}^{2+} / \mathrm{cal}-$ modulin and modulatory transmitter has been proposed to underlie associative changes in the monosynaptic component of the reflex (Abrams, 1985; Abrams and Kandel, 1985, 1988). In this training paradigm, the conditioned stimulus, a weak siphon touch which produces only a small reflex withdrawal, is presented immediately before the unconditioned stimulus, a moderate tail shock which elicits a strong defensive withdrawal response. After a series of these pairings, the response to that same weak conditioned stimulus is substantially enhanced, as if the animal has learned that the siphon touch predicts the noxious tail stimulus (Carew et al., 1981; Hawkins et al., 1986).

At the cellular level, the unconditioned stimulus activates modulatory input to the siphon sensory neurons, the neurons that comprise the afferent pathway for the conditioned stimulus. This modulatory input triggers presynaptic facilitation of synaptic transmission from the siphon sensory neurons to postsynaptic interneurons and motoneurons, thus strengthening the afferent input to the reflex. The response of these sensory neurons to the facilitatory input is enhanced if the sensory neurons are 
causcd to firc action potentials immediately prior to their receiving the facilitatory input (Hawkins et al., 1983; Walters and Byrne, 1983a). Because activity-dependent facilitation in the siphon sensory neurons is likely to be an important contributor to the associative changes produced by conditioning (Hawkins et al., 1983), we probed the underlying associative interactions on both a cellular and a biochemical level.

Conventional presynaptic facilitation of nondepressed synaptic connections from siphon sensory neurons, which occurs when facilitatory input arrives in the absence of paired spike activity, is mediated by an increase in cAMP levels (Brunelli et al., 1976; Bernier et al., 1982; Castellucci et al., 1982). During activity-dependent enhancement of presynaptic facilitation, paired spike activity in the sensory neurons enhances the cAMPdependent changes, including the modulation of presynaptic membrane currents that contributes to synaptic facilitation (Hawkins ct al., 1983; Walters and Byrne, 1983b; I Iawkins and Abrams 1984). Ocorr et al. (1983, 1985) and Abrams et al. (1984) found that, in response to brief applications of the facilitatory transmitter 5-HT, the rise in cAMP in sensory neurons is enhanced if the sensory neurons were caused to fire action potentials or were depolarized just before they were exposed to transmitter. Electrophysiological studies revealed that $\mathrm{Ca}^{2+}$ influx during a train of action potentials was critical for enhancement of the facilitation response by the paired spike activity (Abrams, 1985). These several findings suggested that activitydependent enhancement might occur because the brief elevation of intracellular $\mathrm{Ca}^{2+}$ during a paired train of action potentials increases the synthesis of cAMP stimulated by facilitatory transmitter. According to this view, the conditioned stimulus is represented within the sensory neuron by $\mathrm{Ca}^{2+}$ influx, and the unconditioned stimulus is represented by the action of facilitatory transmitters, such as 5-IIT; the interaction of $\mathrm{Ca}^{2+}$ influx and facilitatory transmitter might occur within the adenylate cyclase system.

The possibility that $\mathrm{Ca}^{2+}$ was modulating the activation of adenylate cyclase by transmitter seemed plausible in light of the finding of Brostrom et al. (1975) and Cheung et al. (1975) that, in mammalian brain, some of the adenylate cyclase is stimulated by $\mathrm{Ca}^{2+}$, via the $\mathrm{Ca}^{2+}$-dependent regulatory protein calmodulin. Eliot et al. (1989) demonstrated that the majority of Aplysia neural cyclase can be stimulated by $\mathrm{Ca}^{2+} /$ calmodulin. Yovell et al. (1986) examined the sensitivity of the cyclase to $\mathrm{Ca}^{2+} /$ calmodulin and found that this enzyme would be stimulated by the normal rise in intracellular $\mathrm{Ca}^{2+}$ that occurs during and immediately after a brief train of action potentials. To explore whether the $\mathrm{Ca}^{2+} /$ calmodulin-sensitive adenylate cyclase in Aplysia neurons provides a molecular site of convergence between the conditioned and the unconditioned stimuli, we have asked whether the same adenylate cyclase molecules that are stimulated by $\mathrm{Ca}^{2+} /$ calmodulin are also activated by transmitter.

When the calmodulin-sensitive cyclase in mammalian brain was first described, there was disagreement about whether the same cyclase that is stimulated by $\mathrm{Ca}^{2+} /$ calmodulin is also activated by a receptor for transmitter or hormone. Activation of adenylate cyclase by a receptor has been shown to be mediated by a coupling protein, the stimulatory $\mathrm{G}$-protein, $\mathrm{G}_{\mathrm{s}}$, which binds GTP when a receptor becomes occupied with agonist; $G_{s}$, in turn, activates the catalytic unit of the cyclase (Schramm and Selinger, 1984). Studies that have tested for dual activation of the cyclase by attempting to determine whether the stimulatory $\mathrm{G}$-protein interacted with calmodulin in activating the enzyme have given inconsistent results. While a number of studies of cyclase in mammalian brain membranes suggested that the stimulatory G-protein activates the same cyclase molecules that are stimulated by $\mathrm{Ca}^{2+} /$ calmodulin (Brostrom et al., 1977, 1978a,b; Seamon and Daly, 1982; Malnoe et al., 1983; Gnegy et al., 1984; Harrison et al., 1988, 1989), other studies suggested a lack of convergence (MacDonald, 1975; Lynch et al., 1977; Salter et al., 1981). Sano and Drummond (1981) reported that solubilized cyclase from cerebral cortex could be separated into two fractions, one that was $\mathrm{Ca}^{2+} /$ calmodulin sensitive and unaffected by activators of $G_{s}$, and a second fraction that was stimulated by $\mathrm{G}_{\mathrm{s}}$ but was not stimulated by $\mathrm{Ca}^{2+}$. More recently, however, several studies of solubilized, partially purified mammalian brain cyclase have indicated that the calmodulin-sensitive catalytic unit is also activated by $\mathrm{G}_{\mathrm{s}}$ (Heideman et al., 1982; Yeager et al., 1985; Rosenberg et al., 1987). In mammals, whether the cyclase is dually activated may depend upon the specific tissue; for example, mammalian sperm cyclase is stimulated by calmodulin but is not known to be activated by either hormones or $G_{s}$ (Gross et al., 1987). In invertebrates, the issue of dual activation remains unresolved; the only relevant analysis was on Drosophila by Livingstone (1985), who concluded that the calmodulin-sensitive population of cyclase was transmitter insensitive. Convergent activation is an essential requirement for the hypothesis, described above, that $\mathrm{Ca}^{2+}$ influx and facilitatory transmitter interact at the level of the cyclase. We therefore carried out experiments designed to determine whether the same adenylate cyclase in Aplysia CNS that is activated by $\mathrm{Ca}^{2+}$ calmodulin is also stimulated by facilitatory transmitter. We show here that convergent, dual activation of the cyclase does occur. We also describe initial experiments designed to explore whether activation of the cyclase is affected by temporal overlap between a transient elevation in $\mathrm{Ca}^{2+}$ and arrival of transmitter.

\section{Materials and Methods}

Preparation of tissue. Aplysia californica, weighing 100-200 gm, were anesthetized by injection of isotonic $\mathrm{MgCl}_{2}$, and their central ganglia were removed. Most experiments were done on desheathed pleural ganglia, the ganglia with the largest population of mechanosensory neurons (Walters et al., 1983). A small number of experiments were done on isolated pleural ganglion sensory neuron clusters. In both cases, the neurons (without sheath) were homogenized on ice in a glass-Teflon homogenizer. In contrast, in experiments on the entire CNS, the abdominal, cerebral, pleural, and pedal ganglia were trimmed to reduce the amount of non-neural tissue (sheath) and homogenized on ice in a glass-glass homogenizer. The homogenate, without the large pieces of sheath, was rehomogenized in a glass-Teflon homogenizer as above. With all three types of material, the homogenate was then centrifuged at $1000 \times g$ for $2 \mathrm{~min}$ to remove large particles. The supernatant was centrifuged at $30,000 \times g$ for $20 \mathrm{~min}$. In experiments using the entire CNS, the pellet was rehomogenized in homogenization buffer (see below) and centrifuged again. The final pellet was rehomogenized in a small volume, $20 \mu \mathrm{l}$ per desheathed pleural ganglion and $500 \mu \mathrm{l}$ per CNS. In most experiments, homogenization was done in the absence of EGTA so that membranes retained substantial endogenous calmodulin (Lynch et al., 1977).

Assay of calmodulin inhibitors. Potential calmodulin inhibitors were screened by testing for inhibition of $\mathrm{Ca}^{2+} /$ calmodulin activation of phosphodiesterase in Aplysia neural tissue. Desheathed pleural ganglia were homogenized in a glass-glass homogenizer and centrifuged at 13,000 $\times$ $g$. Phosphodiesterase activity in the supernatant was assayed (Kauvar, 1982) with free $\mathrm{Ca}^{2+}$ at $10 \mathrm{nM}$ or $1 \mathrm{~mm}$ to assess $\mathrm{Ca}^{2+}$ stimulation. $\mathrm{Ca}^{2+}$ (in the presence of endogenous calmodulin) stimulated phosphodiesterase activity by approximately $60 \%$. Compounds tested for their inhibition of $\mathrm{Ca}^{2+}$ stimulation included melitin, trifluoperazine (TFP; Sigma), R24571 (calmidazolium; Boehringer Mannheim), and W7 (Seikagaku America, St. Petersburg, FL). R24571, trifluoperazine, and 
W7 were maximally effective at concentrations of $5 \mu \mathrm{M}, 50-100 \mu \mathrm{M}$, and $1 \mathrm{~mm}$, respectively; these efficacies are consistent with those for inhibition of Aplysia calmodulin-dependent protein kinase reported by DeRiemer et al. (1984). Melitin (Sigma) was ineffective in the range of concentrations that we tested [up to $10 \mu \mathrm{M}$, which is 10 times the maximally effective concentration in vertebrate studies (Barnette et al., 1983)]. The efficacies of R24571 and trifluoperazine in inhibiting $\mathrm{Ca}^{21} / \mathrm{cal}$ modulin stimulation of adenylate cyclase were then verified. (A small number of experiments were also conducted using $\mathrm{W} 7$; W7 produced similar effects as the other two compounds, though it required substantially higher concentrations.)

Solutions. All buffers contained $50 \mathrm{~mm} \mathrm{K-HEPES,} 1$ mM dithiothreitol (DTT), and protease inhibitors $(10 \mu \mathrm{g} / \mathrm{ml}$ leupeptin, $10 \mu \mathrm{g} / \mathrm{ml}$ aprotonin, and $50 \mu \mathrm{g} / \mathrm{ml}$ PMSF). Except when indicated, homogenization buffer was $\mathrm{pH} 8.0$ and contained no additional components. Other buffers contained additional components, listed below. Cyclase solubilization buffer consisted of $1 \mathrm{~mm}$ EDTA and $250 \mathrm{~mm}$ sucrose, $\mathrm{pH}$ 7.5. G-protein solubilization buffer consisted of $1 \mathrm{~mm}$ EDTA, $250 \mathrm{~mm}$ sucrose, $10 \mathrm{~mm}$ $\mathrm{MgCl}_{2}$, and $800 \mathrm{~mm} \mathrm{NaCl}$, pH 8.0. CHAPS chromatography buffer consisted of $10 \mathrm{mM}$ CHAPS, $10 \mathrm{mM} \mathrm{MgCl}, 1 \mathrm{~mm}$ EDTA, $0.1 \mathrm{mg} / \mathrm{ml}$ human serum albumin (HSA; Schwarz-Mann), and $10 \mu \mathrm{M}$ ATP, pH 8.0. Calmodulin-Sepharose binding buffer consisted of $8 \mathrm{~mm}$ CHAPS, $30 \mathrm{~mm} \mathrm{KCl}, 2 \mathrm{mM} \mathrm{CaCl}_{2}, 5 \mathrm{~mm} \mathrm{MgCl}$, and $0.1 \mathrm{mg} / \mathrm{ml} \mathrm{HSA}, \mathrm{pH} 7.5$. Calmodulin-Sepharose elution buffer consisted of $25 \mathrm{mM} \mathrm{KCl}, 8 \mathrm{~mm}$ CHAPS, 5 mм $\mathrm{MgCl}_{2}$, 5 mм EGTA, 1 mм EDTA, and $0.1 \mathrm{mg} / \mathrm{ml} \mathrm{HSA}$, $\mathrm{pH}$ 7.5. $c y c^{-}$reconstitution buffer consisted of $10 \mathrm{mM} \mathrm{MgCl}_{2}, 1 \mathrm{~mm}$ EDTA, $180 \mathrm{~mm} \mathrm{NaCl}, 0.1 \mathrm{mg} / \mathrm{ml} \mathrm{HSA}$, and $10 \mu \mathrm{M}$ ATP, pH 8.0. Reconstitution buffer consisted of $10 \mathrm{mM} \mathrm{MgCl}_{2}$ and $1 \mathrm{mM}$ EDTA, $\mathrm{pH}$ 8.0. In the temporal pairing experiments, pleural ganglia were homogenized in $50 \mathrm{~mm}$ K-HEPES, pH 7.5 (with $1 \mathrm{~mm}$ DTT and protease inhibitors), plus $200 \mu \mathrm{M}$ EGTA, $60 \mu \mathrm{M} \mathrm{CaCl}_{2}, 6 \mathrm{mM} \mathrm{MgCl}_{2}$, and $10 \mu \mathrm{M}$ GTP and resuspended after centrifugation in $2.5 \mathrm{mM}$ EGTA, $160 \mu \mathrm{M}$ $\mathrm{CaCl}_{2}$, and $6.8 \mathrm{mM} \mathrm{MgCl}_{2}$, pH 7.5 (free $\mathrm{Ca}^{2+}$, approximately $5 \mathrm{nM}$ ). In these pairing experiments, elevations in $\mathrm{Ca}^{2+}$ were achieved by adding buffer with $\mathrm{CaCl}_{2}$ and $\mathrm{MgCl}_{2}$ to bring the total concentrations of $\mathrm{Ca}^{2+}$ to $800 \mu \mathrm{M}$, of $\mathrm{Mg}^{2+}$ to $6.8 \mathrm{~mm}$, and of EGTA to $1.8 \mathrm{~mm}$ (free $\mathrm{Ca}^{2+}$, approximately $0.1-0.2 \mu \mathrm{M}$, after an initial transient of $>100 \mu \mathrm{M}$ free $\mathrm{Ca}^{2+}$ ); free $\mathrm{Mg}^{2+}$ remained approximately $5 \mathrm{mM}$ throughout the experiment. To terminate the $\mathrm{Ca}^{2+}$ pulse, buffer with EGTA and $\mathrm{MgCl}_{2}$ was added to bring the total concentrations of $\mathrm{Ca}^{2+}$ to $640 \mu \mathrm{M}$, of $\mathrm{Mg}^{2+}$ to $8.3 \mathrm{~mm}$, and of EGTA to $10 \mathrm{~mm}$ (free $\mathrm{Ca}^{2+}$, approximately $5 \mathrm{nM}$ ). For the trifluoperazine preexposure experiments, $\mathrm{Ca}^{2+} /$ EGTA buffers that yielded a free- $\mathrm{Mg}^{2+}$ concentration of $2 \mathrm{~mm}$ and a range of free $\mathrm{Ca}^{2+}$ concentrations were prepared according to the method developed by Yovell et al. (1986).

Reconstitution. A fraction from Aplysia CNS containing stimulatory G-protein was prepared using a modification of the protocol described by Hanski et al. (1981). Nervous systems from 50 animals were homogenized in homogenization buffer with $1 \mathrm{~mm}$ EDTA, $\mathrm{pH}$ 8.0. The membranes were centrifuged $(30,000 \times g$ for $20 \mathrm{~min})$ and rehomogenized and recentrifuged two more times. The membranes were then resuspended in G-protein solubilization buffer and centrifuged once again. The pellet was suspended in $1 \mathrm{ml}$ of the same buffer with $1.25 \%$ cholate and $0.1 \mathrm{mg} / \mathrm{ml} \mathrm{HSA}$ and shaken at $0^{\circ} \mathrm{C}$ for $70 \mathrm{~min}$, with occasional vortexing. After solubilization, $10 \mathrm{~mm} \mathrm{MgCl}$ and $1 \mathrm{~mm}$ ATP were added, and the material was centrifuged at $100,000 \times g$ for $1 \mathrm{hr}$. The supernatant was diluted in CHAPS chromatography buffer and concentrated to approximately $1 \mathrm{ml}$ by centrifugation in a Centricon 30 tube. The concentrated material was fractionated by size-exclusion FPLC at $4^{\circ} \mathrm{C}$ in CHAPS chromatography buffer using a Superose 6 column and a Superose 12 column, in series (each column was $30 \mathrm{~cm}$ in length; Pharmacia). Fractions were assayed for cyclase activity, and those containing cyclase were discarded. The fractions were also assayed for the presence of $\mathrm{G}_{\mathrm{s}} \alpha$, by its fluoride-dependent stimulation of the cyclase activity in membranes from the $c y c^{-}$strain of the $S 49$ lymphoma cell line, a mutant lacking $\mathrm{G}_{\mathrm{s}} \alpha$ (Ross et al., 1978). Reconstitution of $\mathrm{G}_{\mathrm{s}}$ with $c y c^{-}$membranes was done as follows: $3 \mu \mathrm{l}$ of each fraction were added to $12 \mu \mathrm{l}$ of $c y c^{-}$membranes $(0.35 \mathrm{mg} / \mathrm{ml}$ protein $)$, then diluted with 10 $\mu \mathrm{l}$ of $c y c^{-}$reconstitution buffer and incubated for $15 \mathrm{~min}$ at $0^{\circ} \mathrm{C}$. A second incubation was done with $25 \mu \mathrm{M} \mathrm{ATP}$, with and without fluoride $\left(50 \mathrm{~mm} \mathrm{NaF}\right.$ with $60 \mu \mathrm{M} \mathrm{AlF}_{3}$ as an activator) for $10 \mathrm{~min}$ at $30^{\circ} \mathrm{C}$. Cyclase activity was then assayed by addition of ${ }^{32} \mathrm{P}$-ATP and other assay components. The peak fractions containing $G_{s} \alpha$ (see Fig. 4) were then preactivated by incubating them with $100 \mu \mathrm{M}$ GTP $\gamma \mathrm{S}$ in the presence of $60 \mathrm{mM} \mathrm{Mg}^{2+}$ for $100 \mathrm{~min}$ at $30^{\circ} \mathrm{C}$. The preactivated material was desalted by ultrafiltration on Centricon 30 filters in CHAPS chro- matography buffer (with $8 \mathrm{~mm}$ CHAPS) to remove free GTP $\gamma \mathrm{S}$, then aliquoted and frozen.

Calmodulin-binding adenylate cyclase was isolated by calmodulinSepharose affinity chromatography (Westcott ct al., 1979) using the procedure described by Eliot et al. (1989) with minor modifications. Prior to each reconstitution experiment, pleural ganglia from 50 animals were desheathed and homogenized in homogenization buffer with $5 \mathrm{mM}$ EGTA. The material was centrifuged and rehomogenized twice in the EGTA buffer to deplete endogenous calmodulin. The final pellet was resuspended in cyclase solubilization buffer and centrifuged once again. The pellet was suspended in $2 \mathrm{ml}$ solubilization buffer with $0.1 \mathrm{mg} / \mathrm{ml}$ HSA and $1.5 \%$ Lubrol and shaken at $0^{\circ} \mathrm{C}$ for $70 \mathrm{~min}$, with occasional vortexing. After solubilization, $10 \mathrm{~mm} \mathrm{MgCl}_{2}$ and $1 \mathrm{~mm}$ ATP were added, and the material was centrifuged $1 \mathrm{hr}$ at $100,000 \times \mathrm{g}$. The supernatant was diluted with $1 \mathrm{ml}$ binding buffer, brought to $2 \mathrm{~mm}$ $\mathrm{CaCl}_{2}$ and $30 \mathrm{~mm} \mathrm{KCl}$, and incubated, with rotation, with $1 \mathrm{ml}$ of calmodulin-Sepharose (Pharmacia) for $3 \mathrm{hr}$ at $4^{\circ} \mathrm{C}$. The resin was then transferred to a column and washed with $80 \mathrm{ml}$ of binding buffer. The calmodulin-binding cyclase was then eluted with $4 \mathrm{ml}$ of elution buffer. The eluted material from calmodulin-Sepharose was thoroughly desalted and concentrated by ultrafiltration on Centricon 30 filters in CHAPS chromatography buffer, without ATP, that contained $10 \mu \mathrm{M}$ forskolin (Behring Diagnostics) to stabilize the enzyme (Smigel, 1986).

Reconstitution of the fraction containing $G_{s}$ with the fraction containing calmodulin-binding cyclase was achieved with a protocol adapted from Smigel (1986). Aliquots of $50 \mu \mathrm{l}$ of this material were added to equal volumes $(50 \mu \mathrm{l})$ of $1.5 \mathrm{mg} / \mathrm{ml}$ dioleolylphosphatidylcholine (in reconstitution buffer). This mixture was shaken with $20 \mathrm{mg}$ of SM-2 beads (Bio-Rad) for $15 \mathrm{~min}$ at $4^{\circ} \mathrm{C}$, and then diluted with $300 \mu l$ of the reconstitution buffer with $1 \mu \mathrm{M}$ forskolin and again shaken $20 \mathrm{~min}$ at $4^{\circ} \mathrm{C}$. The material was centrifuged at $13,000 \times g$ for $1 \mathrm{~min}$, and the supernatant (without SM-2 beads) was added in 125- $\mu$ l aliquots to tubes with $5.5 \mathrm{mg}$ of SM-2 beads each. To these tubes, either $13 \mu \mathrm{l}$ of the activated $\mathrm{G}_{\mathrm{s}}$ or an equal volume of $8 \mathrm{~mm}$ CHAPS chromatography buffer was added; the tubes were shaken for $20 \mathrm{~min}$ at $4^{\circ} \mathrm{C}$. $\mathrm{Ca}^{2+} / \mathrm{cal}-$ modulin was then added to selected tubes. The cyclase in each tube was then assayed in triplicate.

Adenylate cyclase assays. Synthesis of cyclic AMP was assayed by a modification of the method of Salomon (1979). The reaction was carried out with membranes or solubilized cyclase in a 50- $\mu$ l volume containing the following: $50 \mathrm{mM} \mathrm{K-HEPES} \mathrm{(pH} \mathrm{7.6),} 50 \mathrm{U} / \mathrm{ml}$ creatine phosphokinase, $5 \mathrm{~mm}$ creatine phosphate, $0.1 \mathrm{mg} / \mathrm{ml} \mathrm{HSA}, 1 \mathrm{~mm} 3$-isobutyl-1methylxanthine (IBMX), $2 \times 10^{4} \mathrm{dpm}{ }^{3} \mathrm{H}$-cyclic AMP (New England, Nuclear, \#TRK 304), and 2-30 × $10^{6} \mathrm{dpm} \alpha^{32} \mathrm{P}-\mathrm{ATP}$ (Amersham, \#PB171). Concentrations of nucleotides, divalent cations, and transmitters varied among experiments and are noted elsewhere. Because Aplysia neural tissues yielded limited amounts of membrane protein and low total cyclase activity, ${ }^{32} \mathbf{P}$-cAMP synthesized per assay tube was increased by using low concentrations of cold ATP, typically $20 \mu \mathrm{M}$. Assay mixtures were incubated $2-6 \mathrm{~min}$ at $25^{\circ} \mathrm{C}$. Assays of solubilized cyclase were carried out for $10 \mathrm{~min}$. In preliminary experiments, synthesis of cyclic AMP was found to be linear with time over the durations used. Cyclic AMP synthesized was isolated by successive cation exchange (Dowex 50W-X4, Bio-Rad) and neutral alumina (Sigma) chromatography. ${ }^{3} \mathrm{H}$-cyclic AMP included in the assay solution permitted normalization for recovery in calculating cyclic AMP synthesized.

\section{Results}

Exogenous calmodulin can overcome effects of calmodulin inhibitors in reducing stimulation of the cyclase by transmitter As an initial approach to determining whether, in the Aplysia CNS, calmodulin influences activation of adenylate cyclase by transmitter, we tested the effects of calmodulin inhibitors on transmitter stimulation. Two inhibitors, R24571 and TFP, were found in preliminary experiments to be effective in blocking $\mathrm{Ca}^{2+}$ stimulation of calmodulin-dependent phosphodiesterase and cyclase in Aplysia (see Materials and Methods). In further preliminary experiments, the stimulation of the cyclase by the facilitatory transmitter 5-HT in the presence of $100 \mu \mathrm{M}$ free $\mathrm{Ca}^{2+}$ was found to be decreased by either $4 \mu \mathrm{M}$ R24571 or $100 \mu \mathrm{M}$ TFP. 

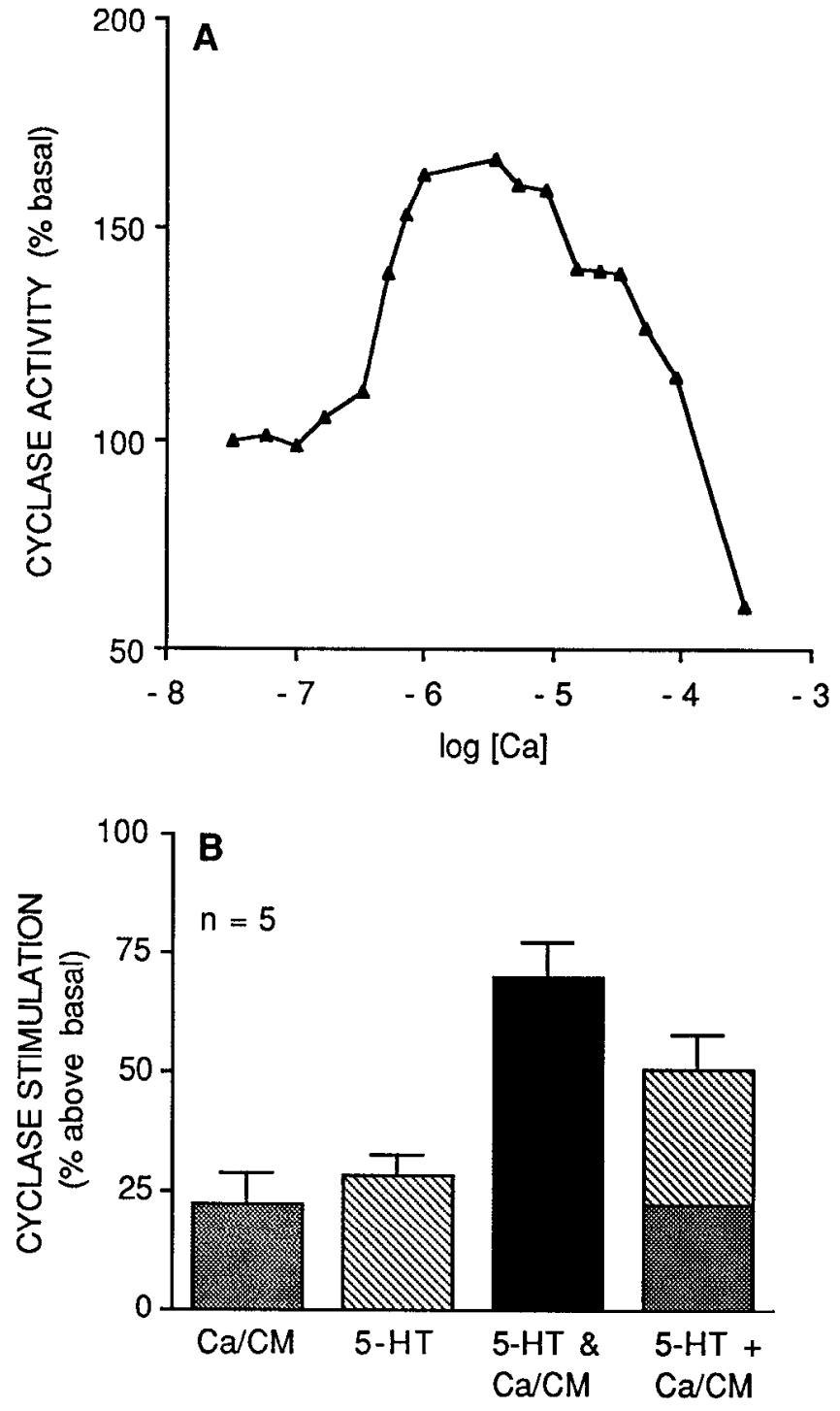

Figure 1. Exogenous calmodulin partially reverses effects of TFP. A, $\mathrm{Ca}^{2+}$ sensitivity of cyclase. To detcrminc optimal levels of $\mathrm{Ca}^{2+}$ to use in these experiments, membranes from Aplysia CNS were assayed in a series of buffers prepared according to the methods of Yovell et al. (1988). Free $\mathrm{Mg}^{2+}$ in assays was $2 \mathrm{~mm}$; added calmodulin was $3 \mu \mathrm{M}$. Data are from a single experiment. Cyclase activity is expressed as percentage of basal with $10 \mathrm{nM}$ free $\mathrm{Ca}^{2+}$ in the presence of calmodulin. $B, \mathrm{Ca}^{2+} /$ calmodulin and 5-HT stimulation of membranes preexposed to TFP. After exposure to $200 \mu \mathrm{M}$ TFP, membranes from Aplysia CNS were centrifuged and resuspended in buffer without the calmodulin inhibitor (it was necessary to remove the TFP from the buffer before adding exogenous calmodulin so that the inhibitor would not saturate the exogenous calmodulin). Assays were conducted in either $30 \mathrm{~nm}$ free $\mathrm{Ca}^{2+}$ (basal conditions) or $3 \mu \mathrm{M}$ free $\mathrm{Ca}^{2+}$ (high $\mathrm{Ca}^{2+}$ conditions). Stimulation of cyclase by $\mathrm{Ca}^{2+}$ with exogenous calmodulin $(\mathrm{Ca} / \mathrm{CM})$, by 10 $\mu \mathrm{M} 5$-HT, or by 5-HT simultaneously with $\mathrm{Ca}^{2+} /$ calmodulin (5-HT \& $\mathrm{Ca} / \mathrm{CM}$ ) are expressed as percentage above basal activity. The sum of the separate stimulations by $5-\mathrm{HT}$ and $\mathrm{Ca}^{2+} /$ calmodulin is also shown $(5-H T+C a / C M)$. Average basal cyclase activity was approximately $15 \mathrm{pmol} \mathrm{cAMP} / \mathrm{mg} \cdot \mathrm{min}$. Data are means $\pm \mathrm{SEM}$ for five separate experiments, each assayed in quadruplicate. The simultaneous stimulation by the two ligands was significantly greater than the sum of the independent stimulations by the two ligands separately $(p<0.02$, twotailed $t$ test). (In the absence of added calmodulin, the increase in free $\mathrm{Ca}^{2+}$ from $30 \mathrm{nM}$ to $3 \mu \mathrm{M}$ resulted in a $14.3 \pm 3.9 \%$ inhibition of cyclase activity; data not shown.) Assays were conducted with $20 \mu \mathrm{M}$ ATP in the presence of $10 \mu \mathrm{M}$ GTP.
One explanation of these results is that the transmitter-activated cyclase in Aplysia CNS could also be regulated by $\mathrm{Ca}^{2+}$ calmodulin. Alternatively, these inhibitors might have interfered with transmitter stimulation in some nonspecific manner. To explore further whether calmodulin influences the stimulation of cyclase by transmitter, we examined whether the effect of TFP could be reversed by the addition of exogenous calmodulin. To detcrminc whether exogenous calmodulin can restore transmitter stimulation, membranes were preexposed to $200 \mu \mathrm{M}$ TFP prior to the assay, then centrifuged and resuspended in buffer without TFP. Because TFP is lipophilic, this procedure leaves substantial amounts of the inhibitor in the membrane (see below); this TFP in the membranes effectively reduced $\mathrm{Ca}^{2+}$ stimulation of the cyclase even after they were resuspended in buffer lacking TFP.

If the TFP in the membranes were exerting its effects nonspecifically by inhibiting some component of the adenylate cyclase complex other than calmodulin, we would expect that exogenous calmodulin would not improve stimulation by transmitter. On the other hand, if the TFP were influencing transmitter stimulation by binding to and inhibiting the endogenous calmodulin, we would expect that exogenous calmodulin, added to the TFP-free buffer, might interact with the cyclase and overcome the effects of the inhibitor in the membranes (Gross et al., 1987).

Two $\mathrm{Ca}^{2+} /$ EGTA buffers were selected for these experiments, one in which free $\mathrm{Ca}^{2+}$ was $3 \times 10^{-8} \mathrm{M}$, which gave no $\mathrm{Ca}^{2+}$ stimulation, and one in which free $\mathrm{Ca}^{2+}$ was $3 \times 10^{-6} \mathrm{M}$, which gave optimal $\mathrm{Ca}^{2+}$ stimulation (Fig. $1 A$ ). In contrast to the stimulation observed in untreated membranes with $\mathrm{Ca}^{2+}$ concentrations of $1-100 \mu \mathrm{M}$, cyclase activity in TFP-pretreated membranes showed modest inhibition by $3 \mu \mathrm{M} \mathrm{Ca}^{2+}$ (data not shown). After addition of $3 \mu \mathrm{M}$ exogenous bovine brain calmodulin, cyclase activity in pretreated membranes showed stimulation by $3 \mu \mathrm{M} \mathrm{Ca}^{2+}$, though less than in untreated membranes $(30 \%$ vs $67 \%$ stimulation in one experiment in which membranes with and without TFP pretreatment were compared; also cf. Fig. $1 A, B)$. In the absence of exogenous calmodulin, stimulation by $10 \mu \mathrm{M} 5$-HT in pretreated membranes was invariably weak. Addition of $\mathrm{Ca}^{2+} /$ calmodulin improved this 5-HT stimulation. In five experiments on separate preparations, the simultaneous stimulation of the cyclase by the two ligands was consistently greater than the sum of the separate stimulations by $\mathrm{Ca}^{2+} / \mathrm{cal}$ modulin and by transmitter (Fig. $1 B$ ). Although this difference was small $(19.6 \pm 4.3 \%$, mean \pm SEM), it was significant ( $p<$ 0.02 , two-tailed $t$ test), suggesting that $\mathrm{Ca}^{2+} /$ calmodulin and facilitatory transmitter interact in activating some of the same cyclase molecules.

An alternative explanation for this reversal of inhibition by exogenous calmodulin could be that the added $\mathrm{Ca}^{2+} / \mathrm{calmodulin}$ binds and removes TFP located within the membrane. Rather than substituting for the endogenous calmodulin in interacting with the cyclase, the calmodulin added might merely decrease the effective concentration of the inhibitor. 'Io test for this possibility, CNS membranes were preexposed to $200 \mu \mathrm{M}{ }^{3} \mathrm{H}-\mathrm{TFP}$, centrifuged, and resuspended in buffer without TFP, with the identical procedure used with the experimental cyclase preparation. By centrifuging these membranes once more and counting the pellets and supernatants, we calculated the relative amount of inhibitor remaining in the membranes after incubation with and without $\mathrm{Ca}^{2+}$ and calmodulin. The membranes concentrated 


\begin{tabular}{|c|c|c|c|}
\hline & Control & $+\mathrm{GTP} \gamma \mathrm{S}$ & GTP $\gamma \mathrm{S}$ stimulation \\
\hline Low $\mathrm{Ca}^{2+}$ & 3.6 & 137 & 133 \\
\hline High $\mathrm{Ca}^{2+}$ & 6.7 & 188 & 181 \\
\hline $\mathrm{Ca}^{2+}$ stimulation & 3.1 & 51 & - \\
\hline
\end{tabular}

Membrane pellets from whole CNS were resuspended in homogenization buffer with $10 \mathrm{mM} \mathrm{MgCl}_{2}$ and divided into two equal portions. One portion ( $+\mathrm{GTP} \gamma \mathrm{S}$ ) was preactivated by incubating it for $3 \mathrm{~min}$ at room temperature with $100 \mu \mathrm{M}$ GTP $\gamma$ S plus $100 \mu \mathrm{M} 5-\mathrm{HT}$. The other portion (control) was similarly incubated without transmitter or guanyl nucleotide. Both portions of membrane were then centrifuged twice more before resuspension for assay. Values are pmol cAMP/ $\mathrm{mg} \cdot \mathrm{min}$.

the inhibitor so that, after resuspension in TFP-free buffer, they contained a minimum of $5 \mathrm{~mm}$ TFP (bascd on an cstimate of the volume of the pellets obtained by centrifuging the resuspended membranes). Exposure to calmodulin in the presence of $3 \mu \mathrm{M} \mathrm{Ca}^{2+}$ resulted in a 14-20\% decrease in the amount of the inhibitor remaining within the membranes. Such a small decrease in the TFP concentration within the membrane fraction is unlikely to reduce effectively any nonspecific effects the inhibitor may have, unless the TFP is selectively removed from a site at which it acts nonspecifically to inhibit the cyclase. While not conclusive, the reversal of the TFP inhibition of 5-HT stimulation by exogenous calmodulin suggests that the TFP is exerting its action specifically, by inhibiting endogenous calmodulin.

\section{Interaction between $G_{s}$ and $\mathrm{Ca}^{2+} /$ calmodulin in activating cyclase}

These TFP preexposure experiments suggested that the same adenylate cyclase can be influenced by two signals, $\mathrm{Ca}^{2+} / \mathrm{cal}-$ modulin and transmitter. Another way to test whether such dual activation occurs is to determine whether the $\mathrm{Ca}^{2+} /$ calmodulinsensitive cyclase can also be activated by the stimulatory G-protein, $G_{s}$. In those systems that have been studied, receptor has been found to be coupled to the catalytic unit of cyclase by means of $G_{s}$ (Schramm and Selinger, 1984). Although $G_{s}$ has not been directly shown to mediate receptor activation of the cyclase catalytic unit in Aplysia, Castellucci et al. (1983) found that, in sensory neurons, cyclase-mediated effects of transmitter were blocked by GDP $\beta$ S, and Volterra et al. (1987) found that GTP $\gamma$ S mimicked these effects; moreover, Vogel et al. (1989) have identified immunoreactive $\mathrm{G}_{\mathrm{s}}$ in Aplysia CNS. Indeed, we found transmitter stimulation of cyclase from Aplysia CNS required the presence of the guanyl nucleotide GTP, which is necessary for $\mathrm{G}_{\mathrm{s}}$-mediated activation (Fig. 2). These several results suggest that, as in other systems, receptor activation of cyclase occurs via an intermediary G-protein that hinds GTP.

To examine whether the same $\mathrm{Ca}^{2+} /$ calmodulin sensitive cyclase is also activated by $G_{s}$, we determined whether $G_{s}$ alters the $\mathrm{Ca}^{2+}$ stimulation of the enzyme. For this purpose, we preactivated $\mathrm{G}_{\mathrm{s}}$ by incubating membranes with the nonhydrolyzable GTP analog GTP $\gamma$ S. As shown in Table 1, after activation by GTP $\gamma \mathrm{S}$, the $\mathrm{Ca}^{2+}$ stimulation increased dramatically, by more than 17 -fold. The stimulation by GTP $\gamma \mathrm{S}$ was also greater, by about $36 \%$, in the presence of $\mathrm{Ca}^{2+}$ than in its absence. It should be noted that, though the dual activation by $\mathrm{G}_{\mathrm{s}}$ together with $\mathrm{Ca}^{2+} /$ calmodulin was greater than the sum of the two separate

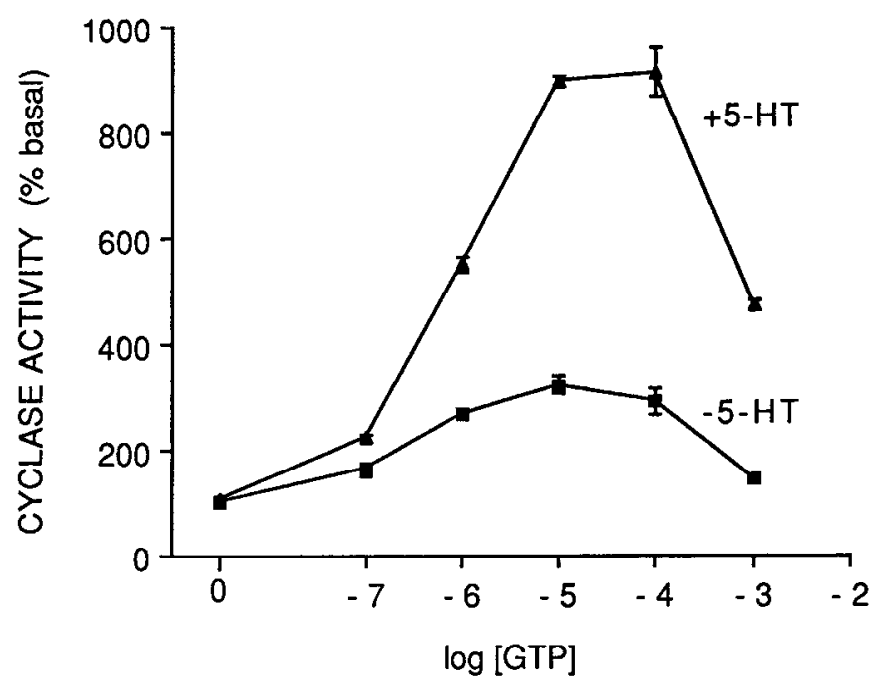

Figure 2. GTP dependence of cyclase stimulation by transmitter. Cyclase activity in membranes from the entire CNS was assayed with and without $20 \mu \mathrm{M} 5-\mathrm{HT}$ at four different concentrations of GTP. Note that 5-HT stimulation is negligible with $100 \mathrm{nM}$ GTP and improves with increasing GTP. Cyclase activity is expressed as percent of basal activity (without added guanyl nucleotides or 5-HT), which was $5.1 \mathrm{pmol}$ cAMP/ $\mathrm{mg} \cdot \mathrm{min}$. Data are the mean $\pm \mathrm{SD}$ for three replicates from a single experiment. A similar dependence of transmitter stimulation on GTP was observed in two other experiments. Assays were conducted with $20 \mu \mathrm{M}$ ATP.

stimulations by $\mathrm{G}_{\mathrm{s}}$ and $\mathrm{Ca}^{2+} /$ calmodulin, the dual stimulation was less than multiplicative. Nevertheless, these results suggest dual activation of a single species of cyclase. If $\mathrm{G}_{\mathrm{s}}$ and $\mathrm{Ca}^{2+} /$ calmodulin were activating separate cyclases, then the absolute stimulation of cAMP synthesis by $\mathrm{Ca}^{2+}$ would be identical whether or not an independent, calmodulin-insensitive species of cyclase had been activated by $\mathrm{G}_{\mathrm{s}}$. Clearly the two stimulations interact and are not independent, consistent with convergent activation of the $\mathrm{Ca}^{2+} /$ calmodulin-sensitive adenylate cyclase.

\section{Reconstitution of stimulatory $G$-protein with the calmodulin-} binding cyclase

The possibility of dual activation can be tested more directly by isolating the cyclase that binds to calmodulin and determining whether this same enzyme can be activated by the stimulatory G-protein. The calmodulin-sensitive cyclase was isolated from other species of adenylate cyclase that may exist in Aplysia CNS by calmodulin-Sepharose affinity chromatography (Westcott et al., 1979; Yeager et al., 1985; Eliot et al., 1989). In an attempt to enrich the experimental preparation for the mechanosensory neurons that show activity-dependent facilitation, we carried out these experiments on desheathed pleural ganglia, the ganglia with the greatest abundance of these neurons. Solubilized material from pleural ganglion membranes was incubated with calmodulin-Sepharose in the presence of $\mathrm{Ca}^{2+}$, the resin was washed to remove unbound material, and calmodulin-binding cyclase activity was then eluted with EGTA-containing buffer (Fig. 3; see also Materials and Methods). As expected, the calmodulin-binding cyclase activity was stimulated by addition of $200 \mu \mathrm{M} \mathrm{Ca}^{2+}$ plus bovine brain calmodulin (see Fig. 5). To determine whether this calmodulin-binding adenylate cyclase interacted with the stimulatory $\mathrm{G}$-unit, we prepared a crude $\mathrm{G}_{\mathrm{s}}$ containing fraction from solubilized Aplysia CNS membranes. 


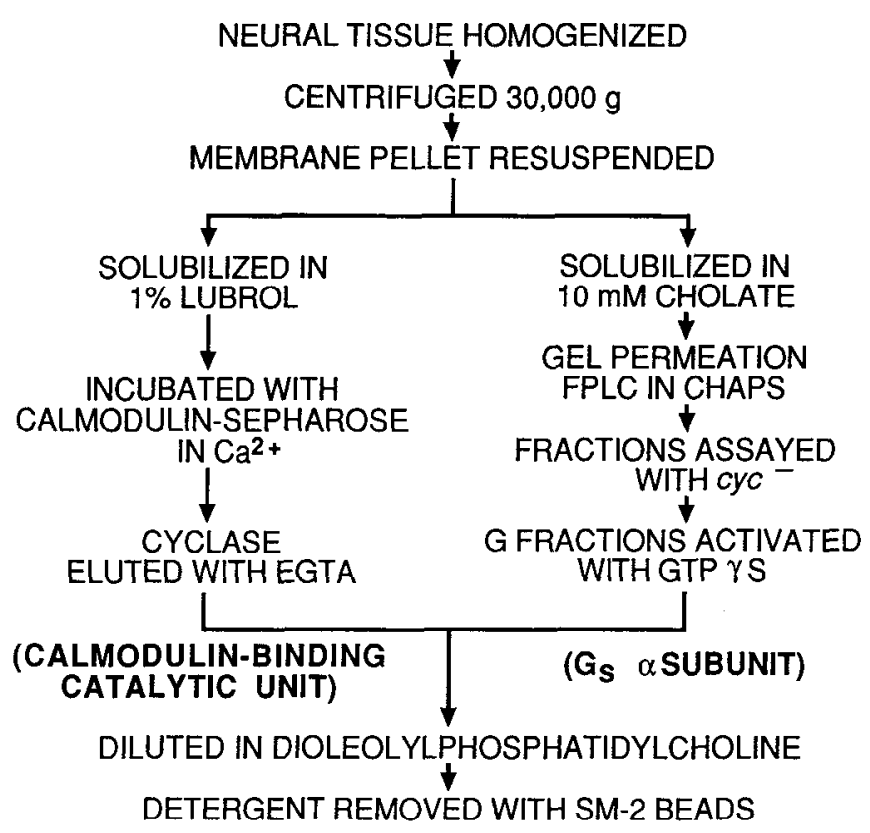

Figure 3. Protocol for reconstitution of $\mathrm{G}_{\mathrm{s}}$ with calmodulin-binding adenylate cyclase in phospholipid. Starting material for partial purification of calmodulin-sensitive adenylate cyclase was desheathed Aplysia pleural ganglia. Starting material for partial purification of $G_{s}$ was entire Aplysia CNS. Additional details are described in Materials and Methods.

The solubilized material was fractionated by size-exclusion chromatography. Fractions containing $\mathrm{G}_{\mathrm{s}} \alpha$ were identified using the $c y c^{-}$lymphoma mutant, which lacks $\mathrm{G}_{\mathrm{s}} \alpha$ (Fig. 4; see also Materials and Methods). The fractions containing the peak $G_{s} \alpha$ activity were preactivated using the nonhydrolyzable GTP analog GTP $\gamma$ S (Fig. 3). Without such preactivation (or without an alternative activator, fluoride), these fractions were unable to activate cyclase (data not shown). The preactivated, partially purified $G_{s}$ was reconstituted with the calmodulin-Sepharose eluate in phospholipid (Smigel, 1986). By itself, the $\mathrm{G}_{\mathrm{s}}$ fraction had no detectable cyclase activity. However, addition of the preactivated $\mathrm{G}_{\mathrm{s}}$ fraction stimulated the calmodulin-binding cyclase $3.6 \pm 1.1$-fold (mean \pm SEM) in five experiments on separate preparations (Fig. 5). In all of these reconstitution experiments, while cyclase stimulation was always observed, the quantitative stimulation by the $\mathrm{G}_{\mathrm{s}}$-containing fraction and by $\mathrm{Ca}^{2+} /$ calmodulin was quite variable; this was possibly a consequence of either inconsistent reconstitution into lipid or varying amounts of degradation of the solubilized enzyme. Whatever the cause of this variability, it prevented us from reliably assessing whether dual stimulation by the $G_{s}$ fraction combined with $\mathrm{Ca}^{2+} /$ calmodulin was greater or less than the sum of the separate stimulations. While we do not yet know which factors affected whether or not synergistic stimulation was observed, we did note that the synergism tended to be stronger when both individual stimulations were weaker.

In these reconstitution experiments, because of the limited amount of membrane proteins available from the Aplysia CNS, neither component was a purified protein; for example, the pleural ganglion membranes from which we purified the calmodulinbinding cyclase provided only approximately $20 \mu \mathrm{g}$ of solubilized membrane protein. Although neither $\mathrm{G}_{\mathrm{s}} \alpha$ nor the catalyst was fully purified, these experiments do provide evidence that the $\mathrm{Ca}^{2+} /$ calmodulin-sensitive cyclase from Aplysia neural tissue

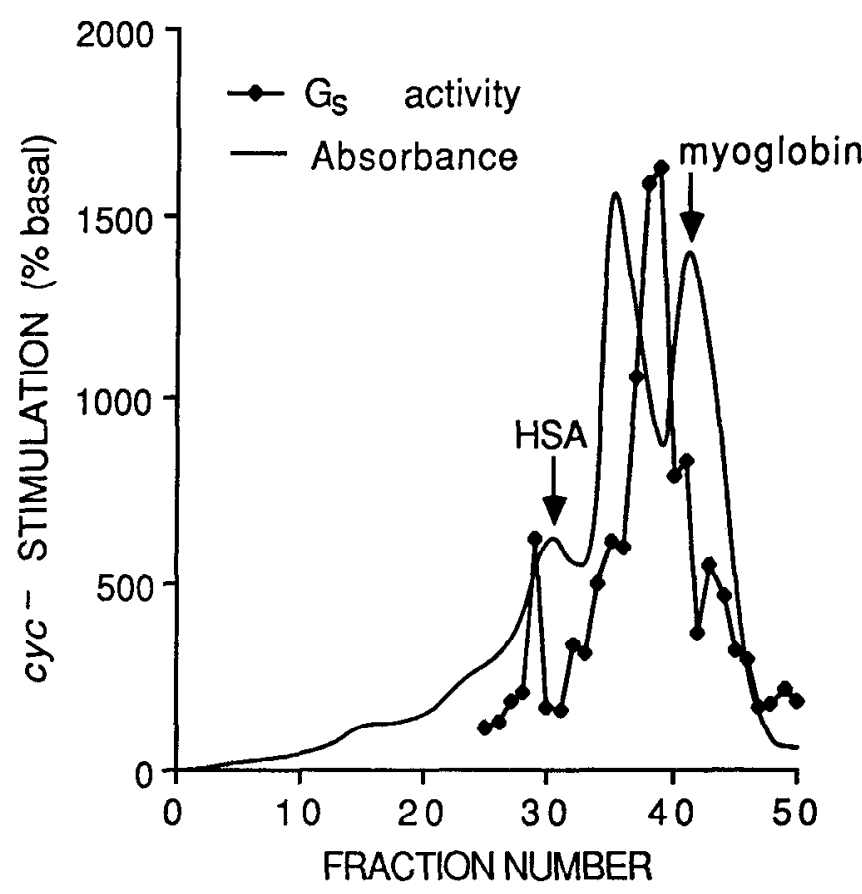

Figure 4. Partial purification of $\mathrm{G}_{\mathrm{s}}$ from Aplysia CNS membranes. CNS membranes were solubilized in cholate, diluted into CHAPS buffer, and fractionated by gel-permeation FPLC. Fractions ( $400 \mu \mathrm{l}$ vol) were assayed for the presence of $G_{s} \alpha$ by reconstituting aliquots of each with membranes from $\mathrm{S} 49$ lymphoma mutant $c y c^{-}$, which lacks $\mathrm{G}_{\mathrm{s}} \alpha . \mathrm{Re}$ constituted membranes were then assayed with or without fluoride, an activator of $\mathrm{G}_{5} \alpha . c y c^{-}$stimulation is the cyclase stimulation by fluoride, as percent above activity in the absence of fluoride; no fluoride stimulation occurs in the absence of $\mathrm{G}_{\mathrm{s}}$. The continuous curve indicates absorbance at $280 \mathrm{~nm}$. Arrows indicate the elution times of peaks representing HSA and myoglobin, which were included with injection of solubilized material as molecular-weight markers. Some $G_{s}$ activity eluted, together with cyclase activity, in the first $8 \mathrm{ml}$; these early fractions were not assayed in the experiment shown in this figure. Cyclase activity was negligible in those fractions that were assayed, fractions 25-50. The two peaks of $\mathrm{G}_{s}$ activity may represent the intact $\alpha \beta \gamma$ heterotrimer, which would be expected to elute before HSA, and the dissociated $\mathrm{G}_{\mathrm{s}}$ unit, which would be expected to elute between HSA and myoglobulin.

can be activated by a stimulatory G-protein. The cyclase activity that we have examined was the activity that binds specifically to calmodulin in a $\mathrm{Ca}^{2+}$-dependent manner (Eliot et al., 1989). Moreover, while the $\mathrm{G}_{\mathrm{s}}$-containing fraction was not fully purified, stimulation of the calmodulin-binding cyclase by this fraction required its preactivation with $\mathrm{GTP}_{\gamma} \mathrm{S}$; this argues that the observed stimulation of the calmodulin-binding cyclase is mediated by a guanyl nucleotide binding protein, probably some species of the stimulatory G-protein, $\mathrm{G}_{\mathrm{s}}$.

\section{Temporal requirements for effective $\mathrm{Ca}^{2+}$-transmitter pairing}

During classical conditioning of the defensive withdrawal reflex, the conditioned stimulus must be temporally paired with the unconditioned stimulus for associative learning to result (Carew et al., 1981, 1983; Hawkins et al., 1986). Similarly, in cellular experiments, action potentials in the sensory neurons must occur immediately before the cells receive facilitatory input for activity-dependent enhancement of the facilitation response to occur (Hawkins et al., 1983; Clark, 1984). We therefore wanted to examine whether convergent activation of the dually activated cyclase by $\mathrm{Ca}^{2+}$ and transmitter could underlie this temporal specificity. Does the elevation in $\mathrm{Ca}^{2+}$ need to overlap 
temporally with the addition of 5-HT for it to enhance stimulation of cyclase?

In order to explore these issues, initial experiments on temporal interactions were conducted with traditional methods in test tubes, in which it was not possible to terminate the exposure to stimulatory transmitter once the transmitter had been added. We tested the effects of brief $\mathrm{Ca}^{2+}$ pulses that were paired or unpaired with 5-HT addition. Experiments were done on membranes from desheathed pleural ganglia that were resuspended in a $\mathrm{Ca}^{2+}$ EGTA buffer with a low level of free $\mathrm{Ca}^{2+}$, approximately $10 \mathrm{nM}$. To pulse $\mathrm{Ca}^{2+}$ in an assay tube, we pipetted in additional $\mathrm{Ca}^{2+}$ to bring the free $\mathrm{Ca}^{2+}$ in the buffer to approximately $0.1-0.2 \mu \mathrm{M}$ and, $10 \mathrm{sec}$ later, pipetted in additional EGI'A to return the free $\mathrm{Ca}^{2+}$ to the initial concentration of approximatcly $10 \mathrm{~nm}$. (Frce $\mathrm{Mg}^{2+}$ was maintaincd at $5 \mathrm{~mm}$ throughout.) For paired stimulation, we added 5-HT in the middle of the $\mathrm{Ca}^{2+}$ pulse; for unpaired stimulation, we added 5-HT $5 \mathrm{sec}$ after the end of the pulse. Tubes were vortexed within $0.5 \mathrm{sec}$ after each addition. Assays were initiated at the same time as the addition of the stimulating ligands and terminated $2.5 \mathrm{~min}$ later.

Although the differences were modest, we consistently observed differences in cyclase stimulation between paired and unpaired $\mathrm{Ca}^{2+}$ and 5-HT addition (Fig. 6). Membranes that received $\mathrm{Ca}^{2+}$ paired with addition of 5-HT showed significantly greater stimulation of cyclase activity than did membranes that received unpaired $\mathrm{Ca}^{2+}$ and 5-HT $(55.6 \pm 10.0 \%$ stimulation above basal for paired vs. $32.6 \pm 5.8 \%$ stimulation above basal for unpaired; the mean difference, with stimulation compared within experiments, was $23.0 \pm 5.9 \% ; p<0.02$, two-tailed $t$ test; data are means \pm SEM). In other experiments, cyclase stimulation when a $\mathrm{Ca}^{2+}$ pulse was paired with 5 -HT addition was compared with stimulation with $5-\mathrm{HT}$ alone. Again, the paired $\mathrm{Ca}^{2+}$ pulse significantly enhanced activation by $5-\mathrm{HT}$ (e.g., in one series of experiments, stimulation was $62.9 \pm 5.2 \%$ for paired $\mathrm{Ca}^{2+}$ and 5 -HT vs. $37.4 \pm 4.1 \%$ for 5 -HT alone; $p$ $<0.05$ ).

One possible explanation for the apparent enhancement of stimulation when $\mathrm{Ca}^{2+}$ and 5-HT overlapped temporally is that there was simply summation of the two separate stimulations by $5-\mathrm{HT}$ and $\mathrm{Ca}^{2+}$. However, such summation cannot account for the differential cyclase stimulation observed because, in the presence of GTP, $\mathrm{Ca}^{2+}$ stimulation is extremely modest (Yovell et al., 1986); these brief, 10-sec pulses of $\mathrm{Ca}^{2+}$ produced no detectable stimulation when delivered alone. In fact, in similar experiments without $5-\mathrm{H} \Gamma$ in which free $\mathrm{Ca}^{2+}$ was increased (as in the pulse experiments), but then left elevated throughout the remainder of the 2.5 -min assay, stimulation was only $6.4 \pm$ $1.5 \%$ of basal activity. Such minimal stimulation by $\mathrm{Ca}^{2+}$ could not explain the enhanced cyclase stimulation observed with pairing.

\section{Discussion}

The cyclase as a molecular site of stimulus convergence Activity-dependent presynaptic facilitation is an associative form of synaptic plasticity that has been implicated in classical conditioning in Aplysia. Studies of activity-dependent facilitation have suggested a specific molecular locus for the associative changes in the sensory neurons. Investigations on intact mechanosensory neurons indicated that the associative enhancement of synaptic transmission might result from interactions between inputs from the conditioned and unconditioned stimuli converging at the $\mathrm{Ca}^{2+} /$ calmodulin-sensitive adenylate cyclasc. Eliot et al. (1989) and Yovell et al. (1986) demonstrated

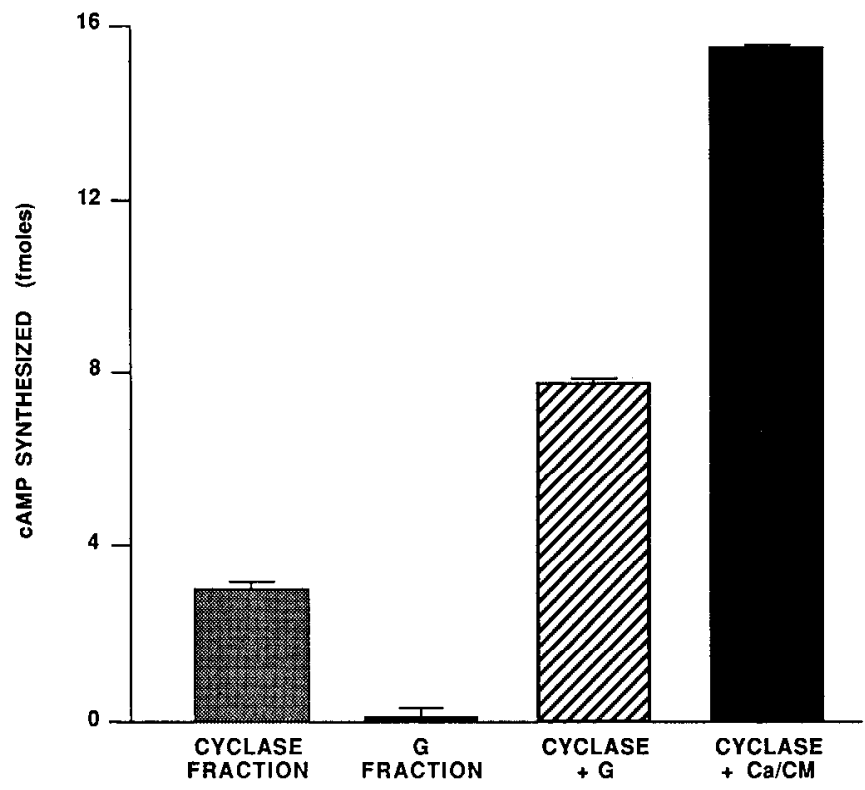

Figure 5. Stimulatory G-protein activates the calmodulin-binding cyclase catalytic unit. EGTA eluate from calmodulin-Sepharose was desalted and reconstituted into phospholipid vesicles, and cyclase activity was assayed alone or with addition of activated $\mathrm{G}_{\mathrm{s}}$-containing fraction or $200 \mu \mathrm{M} \mathrm{Ca}{ }^{2+}$ plus $0.3 \mu \mathrm{M}$ calmodulin. Calmodulin-binding cyclase was stimulated both by activated $\mathrm{G}_{\mathrm{s}}$ and by $\mathrm{Ca}^{2+} /$ calmodulin $(\mathrm{Ca} / \mathrm{CM})$. The $G$ fraction, containing activated $\mathrm{G}_{\mathrm{s}}$, was reconstituted into dioleolylphosphatidylcholine vesicles to which the calmodulin-Sepharose eluate had not becn added. Note that the $G_{\mathrm{s}}$ fraction by itself had negligible cyclase activity. Data for cAMP synthesized are means \pm SD of four replicates from a single, representative reconstitution experiment. Qualitatively similar results were obtained in a total of five other experiments. Assays were without free guanyl nucleotides. [Because total cyclase activity from these solubilized pleural ganglion membranes was quite low, assays were conducted with relatively large amounts of ${ }^{32} \mathrm{P}$-ATP (up to $3 \times 10^{7} \mathrm{cpm}$ per tube) and reduced cold ATP concentrations ( $8 \mu \mathrm{M}$ ATP). Under these assay conditions, basal cyclase activity yielded more than $1500 \mathrm{cpm}{ }^{32} \mathrm{P}$-cAMP per tube; recovery was approximately $80 \%$, and blanks were less than $100 \mathrm{cpm}$.]

that Aplysia CNS contains a species of adenylate cyclase that is stimulated by $\mathrm{Ca}^{2+}$ via calmodulin; the existence of a $\mathrm{Ca}^{2+}$ calmodulin-sensitive cyclase was confirmed by the experiments described above (see, e.g., Figs. 1B, 5).

A critical requirement for the hypothesis that the $\mathrm{Ca}^{2+} / \mathrm{cal}-$ modulin-sensitive cyclase serves an associative role during learning is that the enzyme can be dually regulated. It was therefore essential to determine whether the same adenylate cyclase molecules that can be modulated by $\mathrm{Ca}^{2+}$ influx into the sensory neurons during activity elicited by the conditioned stimulus can also be activated by facilitatory transmitter released by the unconditioned stimulus. To address this issue, we have reconstituted in phospholipid the $\mathrm{Ca}^{2+} /$ calmodulin-sensitive cyclase, isolated using calmodulin-Sepharose, together with a fraction containing stimulatory $\mathrm{G}$-protein, $\mathrm{G}_{\mathrm{s}}$, from Aplysia CNS. These reconstitution experiments demonstrated that the catalytic unit of cyclase that binds to calmodulin in a $\mathrm{Ca}^{2+}$-dependent manner is effectively activated by $\mathrm{G}_{\mathrm{s}}$. Addition of $\mathrm{Ca}^{2+} /$ calmodulin also stimulated this same cyclase. This stimulation by calmodulin is most likely direct, given that the enzyme binds to calmodulinSepharose; alternatively, it could be mediated by a $\mathrm{Ca}^{2+} / \mathrm{cal}-$ modulin-dependent kinase present both in the membrane preparation and in the eluate from calmodulin-Sepharose. 

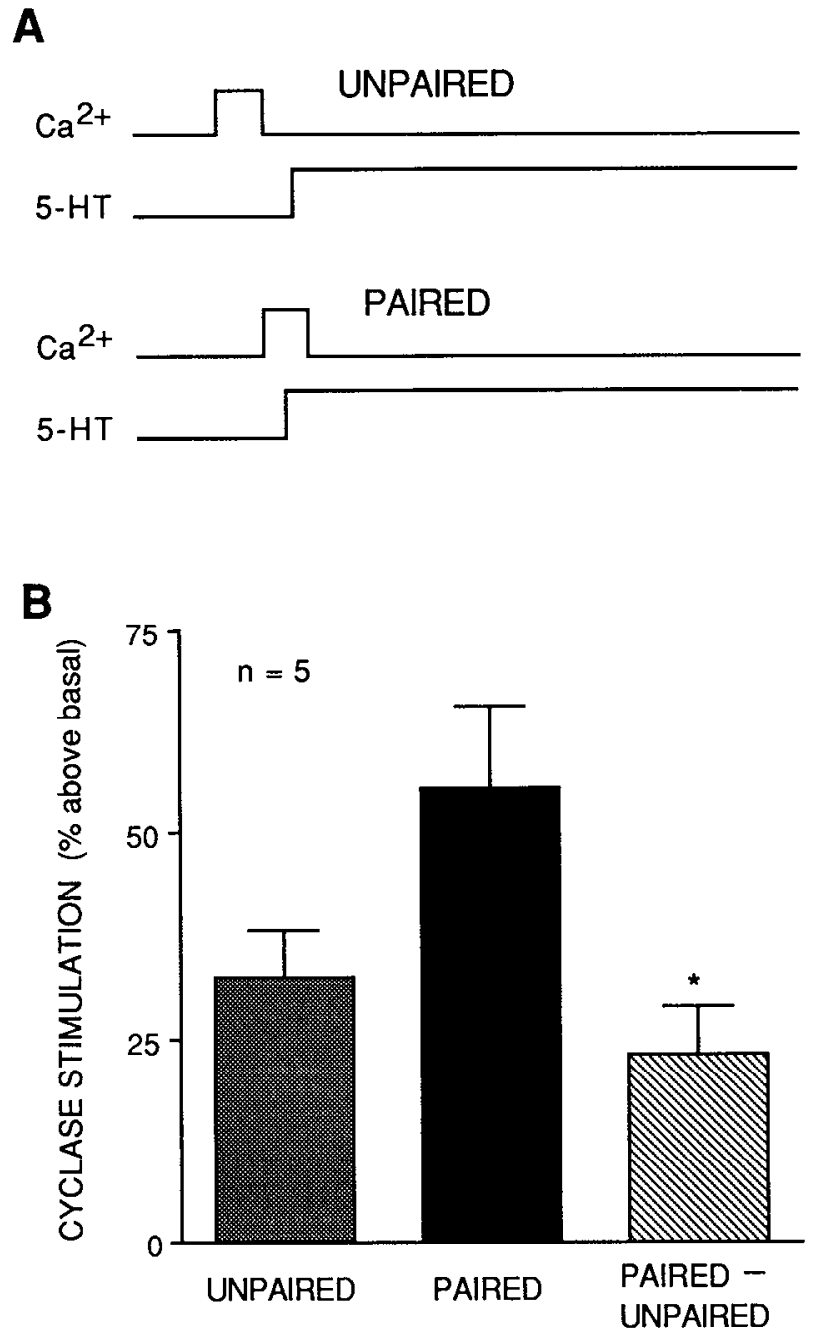

Figure 6. Temporal requirements for effective $\mathrm{Ca}^{2+}-$ transmitter pairing. $A$, Protocol for $\mathrm{Ca}^{2+}$ pulses paired and unpaired with facilitatory transmitter. Homogenized desheathed pleural ganglia were resuspended in a $\mathrm{Ca}^{2+}$-EGTA buffer with $5 \mathrm{nM}$ free $\mathrm{Ca}^{2+}$. During the assay, each tube contained the membranes from approximately one pleural ganglion. $\mathrm{Ca}^{2+}$ transients were achieved by pipetting $\mathrm{Ca}^{2+}$ into a tube, followed $10 \mathrm{sec}$ later by addition of EGTA to reduce the free $\mathrm{Ca}^{2+}$ to the initial low level (see Materials and Methods). Addition of $20 \mu \mathrm{M}$ 5-HT was done either in the middle of the $\mathrm{Ca}^{2+}$ pulse $(P A I R E D)$ or $5 \mathrm{sec}$ after the EGTA addition (UNPAIRED). Assay of cyclase activity was terminated $2.5 \mathrm{~min}$ after $5-\mathrm{H}^{\mathrm{T}}$ addition. Tubes were vortexed immediately after each addition. Assays included $20 \mu \mathrm{M}$ ATP and $10 \mu \mathrm{M}$ GTP, and no added calmodulin (membranes were homogenized and centrifuged in a buffer designed to retain endogenous membrane-bound calmodulin). $B$, Cyclase stimulation by paired and unpaired $\mathrm{Ca}^{2+}$ pulses: results of experiments carried out according to protocol in $A$. Mean of the difference, within each experiment, between stimulation with paired $\mathrm{Ca}^{2+}$ pulse and stimulation with unpaired $\mathrm{Ca}^{2+}$ pulse (right bar) was significantly greater than $0\left(^{*}, p<0.02\right.$, two-tailed $t$ test $)$. Data are means \pm SEM for five experiments, consisting of four or five replicates each. Average basal cyclase activity was approximately $16 \mathrm{pmol} \mathrm{cAMP} / \mathrm{mg} \cdot \mathrm{min}$.

We have not yet carried out the complete reconstitution with receptor, G-protein, and catalyst. However, in all systems that have been sufficiently studied, the stimulatory G-protein serves as a coupling protein, binding GTP and activating the catalyst when agonist binds to the appropriate receptor (Schramm and Selinger, 1984). As in other systems, stimulation of Aplysia neural cyclase by the facilitatory transmitter $5-\mathrm{HT}$ requires the presence of GTP (Fig. 2). Thus, the observation that the $\mathrm{Ca}^{2+}$ / calmodulin-sensitive catalyst can be activated by a $\mathrm{G}_{\mathrm{s}}$-containing fraction suggests that it can bc also activated by transmitter via the stimulatory receptors linked to $\mathrm{G}_{\mathrm{s}}$. The $\mathrm{Ca}^{2+} /$ calmodulinsensitive adenylate cyclase similarly isolated from bovine brain is also activated by the stimulatory G-protein; Heideman et al. (1982) and Yeager et al. (1985) found that, after separation with calmodulin-Sepharose, the bovine catalytic unit remains coupled to $G_{s}$ and is stimulated by ligands that activate $G_{s}$. In contrast, the solubilized Aplysia cyclase appears to separate readily from $G_{s}$, because it usually shows little or no sensitivity to ligands that activate $G_{\mathrm{s}}$ after calmodulin-Sepharose chromatography (L. S. Eliot, unpublished observations). Thus, it was necessary in this study to reconstitute the catalyst with a $\mathrm{G}_{\mathrm{s}}$ fraction to demonstrate activation by the guanyl nucleotidebinding protein.

Additional evidence that the $\mathrm{Ca}^{2+} /$ calmodulin-sensitive adenylate cyclase is also activated by transmitter and stimulatory G-protein comes from the observation that, under some conditions, transmitter and $\mathrm{G}_{\mathrm{s}}$ interact with $\mathrm{Ca}^{2+} /$ calmodulin in stimulating the cyclase in homogenized neural membranes. If the two stimuli were activating separate enzymes, the absolute stimulation by one would be unaffected by activation by the other. As discussed below, the magnitude of this interaction, or synergism, varied substantially, depending upon experimental conditions. Nevertheless, the fact that under some circumstances these interactions occurred must mean that $\mathrm{Ca}^{2+}$ and transmitter converge in stimulating a single species of cyclase.

Because the Aplysia enzyme is dually regulated by calmodulin and by the stimulatory G-protein, it provides a potential site of convergence between the conditioned stimulus, which causes activity and $\mathrm{Ca}^{2+}$ influx in the sensory neurons, and the unconditioned stimulus, which causes release of facilitatory transmitter. This dual regulation of the cyclase contrasts with the conclusion by Livingstone (1985), studying Drosophila cyclase, that a single species of cyclase cannot by itself mediate stimulus convergence during conditioning and that more complex molecular cascades must be postulated to account for the critical roles of $\mathrm{Ca}^{2+}$ influx and the $\mathrm{Ca}^{2+} /$ calmodulin-sensitive cyclase in associative changes during learning.

\section{Can $\mathrm{Ca}^{2+}$ and facilitatory transmitter act synergistically in activating the calmodulin-sensitive cyclase?}

If $\mathrm{Ca}^{2+}$ influx and facilitatory transmitter act associatively to produce an enhanced facilitation response by converging on the cyclase, they may be expected to stimulate the adenylate cyclase synergistically. We consider an activation to be synergistic when the absolute stimulation by two ligands acting simultaneously is greater than the sum of the two separate stimulations produced by each ligand acting alone; thus, synergistic stimulation is greater than additive stimulation. Synergistic activation by two stimulating inputs that overlap in time could underlie the requirement for the pairing of the conditioned and unconditioned stimuli. Alternatively, in the absence of synergism, an associative requirement for dual activation of the cyclase could result from a nonlinear step in the facilitation response downstream from the synthesis of cAMP (e.g., a process with a discrete threshold) that necessitated the coincidence of the two stimuli to achieve a minimum required level of cAMP (see discussion by Yovell and Dudai, 1987). Studies that have sought to identify synergism between the stimulatory G-protein and $\mathrm{Ca}^{2+} /$ calmodulin in activating cyclase in mammalian brain 
membranes have yielded inconsistent results (MacDonald, 1975; Brostrom et al., 1977, 1978b; Treisman et al., 1983). Similarly, in the CNS of Aplysia, we have found that $\mathrm{Ca}^{2+} /$ calmodulin and either transmitter or guanyl nucleotides may produce stimulation that is either greater than or less than additive stimulation, depending upon assay conditions. For example, when solubilized cyclase and a $\mathrm{G}_{\mathrm{s}}$-containing fraction were reconstituted in phospholipid, dual stimulation by the preactivated $G_{s}$ fraction and $\mathrm{Ca}^{2+} /$ calmodulin was greater or less than additive, depending upon the individual experiment; our preliminary observations suggested that the synergism tended to be stronger when the individual effects of $\mathrm{Ca}^{2+} /$ calmodulin and $\mathrm{G}_{\mathrm{s}}$ were weak. In contrast, in experiments on intact membranes, GTP $\gamma \mathrm{S}$ and $\mathrm{Ca}^{2+}$ calmodulin consistently produced more than additive stimulation of the cyclase (Table 1). Eliot et al. (1989) also observed synergistic activation of solubilized bovine brain cyclase by nonhydrolyzable guanyl nucleotides and $\mathrm{Ca}^{2+} /$ calmodulin. Reliable, though weak, synergism was also observed when TFP preexposure was used to inhibit endogenous calmodulin (Fig. 1B). The parameters that affect the extent to which synergism is observed under different assay conditions must still be elucidated. Nevertheless, these experiments, and those in which pulses of $\mathrm{Ca}^{2+}$ were paired with 5-HT, suggest that at least under some conditions $\mathrm{Ca}^{2+} /$ calmodulin may regulate the activation of cyclase by transmitter. As discussed below, under normal conditions (where $G_{s}$ is activated by the natural guanyl nucleotide GTP, and in the absence of calmodulin inhibitors), synergistic activation may be most dramatic when the activating stimuli are transient.

\section{Temporal requirements for effective stimulus pairing}

Perhaps the most interesting prediction from behavioral and electrophysiological studies about associative activation of adenylate cyclase is that there should be precise temporal requirements for the pairing of $\mathrm{Ca}^{2+}$ and transmitter to achieve optimal cyclase activation: (1) $\mathrm{Ca}^{2+}$ and transmitter must overlap temporally, and (2) activation by $\mathrm{Ca}^{2+}$ must begin before activation by transmitter.

Ideally, the interaction between stimuli would be explored with transicnt increases in $\mathrm{Ca}^{2+}$, comparable to the rise in intracellular $\mathrm{Ca}^{2+}$ during a brief $(\leq 0.5 \mathrm{sec})$ train of action potentials, and with transient exposures to facilitatory transmitter, such as would be produced by a short (1-1.5 sec) unconditioned stimulus. The techniques used in the present study were inadequate for a thorough temporal analysis. Nevertheless, our preliminary attempts to test the effects of temporal coincidence indicated that $\mathrm{Ca}^{2+}$ pulses that overlap in time with 5-HT addition were more effective in activating cyclase than $\mathrm{Ca}^{2+}$ pulses that ended before the addition of transmitter (Fig. 6). Thus, this initial study suggests that $\mathrm{Ca}^{2+} /$ calmodulin may serve to prime the cyclase for optimal stimulation by facilitatory transmitter. There are, however, two important limitations to the procedure used in these initial experiments: First, durations of stimuli and intervals between stimuli were long compared with physiological stimuli. For instance, the $10-\mathrm{sec} \mathrm{Ca}^{2+}$ rise in the test tube is probably much longer than the $\mathrm{Ca}^{2+}$ transicnt produccd by a 0.5 -sec train of action potentials in the sensory neuron (M. Spira, H. Blumenfeld, and S. Siegelbaum, personal communication). Second, in our experiments, 5-HT, once added, remained in the membranes for the duration of the assay. In contrast, in the ganglion, the concentration of free facilitatory transmitter probably begins to decline once the unconditioned stimulus has end- ed. Ideally, exposure to facilitatory transmitter should be transient; in electrophysiological experiments, no activity-dependent enhancement of the facilitation response is observed when 5-HT exposures last more than a few sec (Abrams, 1985; T. W. Abrams, unpublished observations). Recent studies have used a modification of the perfused membrane cyclase assay methodology of Yovell et al. (1987) to examine the activation of $A$ plysia neural cyclase by temporally paired transicnt stimuli (Yovell and Abrams, 1988). These results are consistent with the results of the $\mathrm{Ca}^{2+}$ pulse experiments described here in suggesting that, whereas there is no synergism when $\mathrm{Ca}^{2+}$ and transmitter are present for the duration of an assay, $\mathrm{Ca}^{2+} /$ calmodulin may interact to enhance activation by $5-\mathrm{HT}$ when the stimuli are sufficiently brief (Yovell and Abrams, unpublished observations).

Despite the substantial temporal limitations in the present protocol, one interesting observation has emerged: $\mathrm{a} \mathrm{Ca}^{2+}$ pulse that ended $5 \mathrm{sec}$ before 5 -HT was added did not noticeably enhance the stimulation of the cyclase, suggesting that $\mathrm{Ca}^{2+} /$ calmodulin effects on cyclase activation decay in less than $5 \mathrm{sec}$ (Fig. 6, unpaired pulse). Such a rapid decay of the effects of $\mathrm{Ca}^{2+}$ is consistent with the narrow interstimulus interval $(<2 \mathrm{sec})$ for effective stimulus pairing that has been observed behaviorally (Hawkins et al., 1986).

In addition to requiring temporal proximity for effective pairing of conditioned and unconditioned stimuli, a molecular mechanism for associative plasticity during conditioning would be expected to display the sequence requirement observed in behavioral and physiological studies of classical conditioning; that is, the conditioned stimulus, or activity, and $\mathrm{Ca}^{2+}$ influx must precede the unconditioned stimulus, or facilitatory transmitter. Results indicating a possible $\mathrm{Ca}^{2+}-5-\mathrm{HT}$ sequence requirement for optimal cyclase activation have recently been obtained using the perfused membrane cyclase methodology mentioned above (Yovell and Abrams, 1988).

\section{Possible additional sites of stimulus convergence}

Although we have identified one molecular site at which activity and $\mathrm{Ca}^{2+}$ influx can enhance the cAMP-mediated facilitation response, undoubtedly there are other sites of interaction. For example, in several cell types, phosphorylation by the $\mathrm{Ca}^{2+}$ / phospholipid-dependent kinase (kinase C) increases transmitter activation of the cyclase by inactivating the inhibitory G-protein, $\mathrm{G}_{\mathrm{i}}$ (Jakobs et al., 1985; Katada et al., 1985). Thus, this is a second possible mechanism by which $\mathrm{Ca}^{2+}$ could enhance cAMP synthesis. Downstream from adenylate cyclase and cAMP synthesis, there are additional possible sites at which $\mathrm{Ca}^{2+}$ could modulate the facilitation response. Such interactions could diminish, as well as potentiate, cAMP-mediated effects, as Kramer and Levitan (1988) and Kramer et al. (1988) have described in neuron $\mathrm{R} 15$ in Aplysia. In this cell, $\mathrm{Ca}^{2+}$ influx antagonizes modulation by cAMP by activating the $\mathrm{Ca}^{2+} /$ calmodulin-sensitive phosphodiesterase. Similarly, Aplysia sensory neurons contain a calmodulin-sensitive phosphodiesterase (T. W. Abrams and K. A. Karl, unpublished observations) as well as a calmodulin-sensitive cyclase. The predominant effect of $\mathrm{Ca}^{2+}$ elevations on CAMP-mediated processes may depend on the relative abundance of the two enzymes and on the distribution of $\mathrm{Ca}^{2+}$ within the cell; a small influx $\mathrm{Ca}^{2+}$ may be localized near the membrane and may primarily activate the cyclase. The role played by other sites of interaction between activity and the facilitation response in activity-dependent facilitation must be explored in future cellular and biochemical studies. 


\section{Allosteric interactions and associative learning}

Following the initial characterization of proteins that had central roles in neuronal function, such as the ACh receptor, the suggestion was made that allosteric interactions at a single molecule could underlie associative changes during learning (Stent, 1973; Heidmann and Changeux, 1982; Changeux and Heidmann, 1987). Recently, two particular examples of such allosteric interactions have been described in studies of learning and synaptic plasticity in simple neural systems. First, the analysis of activity-dependent facilitation gave rise to the hypothesis that convergence of the conditioned stimulus and unconditioned stimulus at the $\mathrm{Ca}^{2+} /$ calmodulin-sensitive adenylate cyclase could be responsible for the associative synaptic changes. The present study indicates that, in Aplysia, the $\mathrm{Ca}^{2+}$-sensitive cyclase has some of the properties required for it to play such an associative role. Additional support for an associative role for the cyclase comes from the finding that the Drosophila mutant rutabaga, which shows poor learning and memory, has a defect in the function of its $\mathrm{Ca}^{2+} /$ calmodulin-sensitive adenylate cyclase (Dudai and Zvi, 1984; Livingstone et al., 1984; Yovell et al., 1986). Second, recent studies of the mechanism of associative longterm synaptic potentiation in hippocampus suggest that associative activation of the glutamate-gated channel may be responsible for strengthening the synaptic connections (Collingridge et al., 1983; Harris et al., 1984; Kelso et al., 1986; Sastry et al., 1986; Wigstrom et al., 1986). Temporal coincidence of glutamate binding and postsynaptic depolarization is required for effective activation of the NMDA-gated $\mathrm{Ca}^{2+}$ conductance (Nowak et al., 1984; MacDermott et al., 1986); the resulting postsynaptic $\mathrm{Ca}^{2+}$ influx may serve to trigger synaptic plasticity (Lynch et al., 1983; Malenka et al., 1988). Thus, in both Aplysia sensory neurons and hippocampus, associative changes in synaptic connections may not require a complex neuronal circuit, but may result from allosteric interactions at molecules that gate second-messenger-induced plasticity (Abrams and Kandel, 1988).

In conclusion, it should be pointed out that, though the calmodulin sensitivity of adenylate cyclase in mammalian brain was reported more than a decade ago (Brostrom et al., 1975; Cheung et al., 1975), until recently there had been no suggestion as to its functional role. The results reported here are consistent with the possibility suggested by recent cellular studies of learning in Aplysia (Abrams, 1985; Ocorr et al., 1985) and genetic studies of learning in Drosophila (Dudai and Zvi, 1984; Livingstone et al., 1984; Yovell et al., 1986), that the dually regulated calmodulin-sensitive cyclase may play a critical associative role in learning.

\section{References}

Abrams TW (1985) Activity-dependent presynaptic facilitation: an associative mechanism in Aplysia. Cell Mol Neurobiol 5:123-145.

Abrams TW, Kandel ER (1985) Roles of calcium and adenylate cyclase in activity-dependent facilitation, a mechanism for classical conditioning in Aplysia. J Neurochem 44:512.

Abrams TW, Kandel ER (1988) Is contiguity detection in classical conditioning a system or a cellular property? Learning in Aplysia suggests a possible molecular site. Trends Neurosci 11:128-135.

Abrams TW, Bernier L, Hawkins RD, Kandel ER (1984) Possible roles of $\mathrm{Ca}^{2+}$ and cAMP in activity-dependent facilitation, a mechanism for associative learning in Aplysia. Soc Neurosci Abstr 10:269.

Barnette MS, Daly R, Weiss B (1983) Inhibition of calmodulin activity by insect venom peptides. Biochem Pharmacol 32:2929-2933.
Bernier L, Castellucci VF, Kandel ER, Schwartz JH (1982) Facilitatory transmitter causes a selective and prolonged increase in adenosine $3^{\prime}$ : $5^{\prime}$-monophosphate in sensory neurons mediating the gill and siphon withdrawal reflex in Aplysia. J Neurosci 2:1682-1691.

Brostrom CO, Huang YC, Breckenridge BM, Wolff DJ (1975) Identification of a calcium-binding protein as a calcium-dependent regulator of brain adenylate cyclase. Proc Natl Acad Sci USA 72:64-68.

Brostrom CO, Brostrom MA, Wolff DJ (1977) Calcium-dependent adenylate cyclase from rat cerebral cortex. Reversible activation by sodium fluoride. J Biol Chem 252:5677-5685.

Brostrom MA, Brostrom CO, Breckenridge B, Wolff DJ (1978a) Calcium-dependent regulation of brain adenylate cyclase. Adv Cyclic Nucleotide Res 9:85-99.

Brostrom MA, Brostrom CO, Wolff DJ (1978b) Calcium-dependent adenylate cyclase from rat cerebral cortex: activation by guanine nucleotides. Arch Biochem Biophys 191:341-350.

Brunelli M, Castellucci V, Kandel ER (1976) Synaptic facilitation and behavioral sensitization in Aplysia: possible role of serotonin and cyclic AMP. Science 194:1178-1181.

Carew TJ, Walters ET, Kandel ER (1981) Classical conditioning in a simple withdrawal reflex in Aplysia californica. J Neurosci 1:14261437.

Carew TJ, Hawkins RD, Kandel ER (1983) Differential classical conditioning of a defensive withdrawal reflex in Aplysia californica. Science 219:397-400.

Castellucci VF, Nairn A, Greengard P, Schwartz JH, Kandel ER (1982) Inhibitor of adenosine $3^{\prime}: 5^{\prime}$-monophosphate-dependent protein $\mathrm{ki}$ nase blocks presynaptic facilitation in Aplysia. J Neurosci 2:16731681.

Castellucci VF, Bernier L, Schwartz JH, Kandel ER (1983) Persistent activation of adenylate cyclase underlies the time course of shortterm sensitization in Aplysia. Soc Neurosci Abstr 9:169.

Changeux JP, Heidmann T (1987) Allosteric receptors and molecular models of learning. In: Synaptic function (Edelman GM, Gall WE, Cowan WM, eds), pp 549-601. New York: Wiley.

Cheung WY, Bradham LS, Lynch TJ, Lin YM, Tallant EA (1975) Protein activator of cyclic $3^{\prime}: 5^{\prime}$-nucleotide phosphodiesterase of bovine or rat brain also activates its adenylate cyclase. Biochem Biophys Res Commun 66:1055-1062.

Clark GA (1984) A cellular mechanism for the temporal specificity of classical conditioning of the siphon-withdrawal response in Aplysia. Soc Neurosci Abstr 10:268.

Collingridge GL, Kehl SJ, McLennan H (1983) Excitatory amino acids in synaptic transmission in the Schaffer collateral-commissural pathway of the rat hippocampus. J Physiol (Lond) 334:33-46.

DeRiemer SA, Kaczmarek LK, Lai Y, McGuinness TL, Greengard P (1984) Calcium/calmodulin-dependent protein phosphorylation in the nervous system of Aplysia. J Neurosci 4:1618-1625.

Dudai Y, Zvi S (1984) Adenylate cyclase in the Drosophila memory mutant rutabaga displays an altered $\mathrm{Ca}^{2+}$ sensitivity. Neurosci Lett 47:119-124.

Eliot LS, Dudai Y, Kandel ER, Abrams TW (1989) $\mathrm{Ca}^{2+} /$ calmodulin sensitivity may be common to all forms of neural adenylate cyclase. Proc Natl Acad Sci USA 86:9564-9568.

Gnegy ME, Muirhead N, Roberts LJ, Treisman G (1984) Calmodulin stimulates adenylate cyclase activity and increases dopamine activation in bovine retina. J Neurosci 4:2712-2717.

Gross MK, Toscano DG, Toscano WA (1987) Calmodulin-mediated adenylate cyclase from mammalian sperm. J Biol Chem 262:86728676.

Hanski E, Sternweis PC, Northup JK, Dromerick AW, Gilman AG (1981) The regulatory component of adenylate cyclase; purification and properties of the turkey erythrocyte protein. J Biol Chem 256: 12911-12917.

Harris EW, Ganong $\Lambda \mathrm{H}$, Cotman CW (1984) Long-term potentiation in the hippocampus involves activation of $N$-methyl-D-aspartate receptors. Brain Res 323:132-137.

Harrison JK, Mickevicius CK, Gnegy ME (1988) Differential regulation by calmodulin of basal, GTP-, and dopamine-stimulated adenylate cyclase activities in bovine striatum. J Neurochem 51:345352.

Harrison JK, Hewlett GH, Gnegy ME (1989) Regulation of calmodulin-sensitive adenylate cyclase by the stimulatory G-protein, $G_{s}$. J Biol Chem 264:15880-15885.

Hawkins RD, Abrams TW (1984) Evidence that activity-dependent 
facilitation underlying classical conditioning in Aplysia involves modulation of the same ionic current as normal presynaptic facilitation. Soc Neurosci Abstr 10:268.

Hawkins RD, Abrams TW, Carew TJ, Kandel ER (1983) A cellular mechanism of classical conditioning in Aplysia: activity-dependent amplification of presynaptic facilitation. Science 219:400-405.

Hawkins RD, Carew TJ, Kandel ER (1986) Effects of interstimulus interval and contingency on classical conditioning of the Aplysia siphon withdrawal reflex. J Neurosci 6:1695-1701.

Heideman W, Wierman BM, Storm DR (1982) GTP is not required for calmodulin stimulation of bovine brain adenylate cyclase. Proc Natl Acad Sci USA 79:1462-1465.

Heidmann T, Changeux JP (1982) Un modele moleculaire de regulation d'efficacite d'un synapse chimique au niveau postsynaptique. CR Seances Acad Sci (Paris) 295:665-670.

Jakobs KH, Bauer S, Watanabe Y (1985) Modulation of adenylate cyclase of human platelets by phorbol ester. Impairment of the hormone-sensitive inhibitory pathway. Eur J Biochem 151:425-430.

Katada T, Gilman AG, Watanabe Y, Bauer S, Jakobs KH (1985) Protein kinase $\mathrm{C}$ phosphorylates the inhibitory guanine-nucleotide-binding regulatory component and apparently suppresses its function in hormonal inhibition of adenylate cyclase. Eur J Biochem 151:431437

Kauvar LM (1982) Defective cyclic adenosine $3^{\prime}: 5^{\prime}$-monophosphate phosphodiesterase in the Drosophila memory mutant dunce. J Neurosci $2: 1347-1358$.

Kelso SR, Ganong AH, Brown TH (1986) Hebbian synapses in hippocampus. Proc Natl Acad Sci USA 83:5326-5330.

Kramer RH, Levitan IB (1988) Calcium-dependent inactivation of a potassium current in the Aplysia neuron R15. J Neurosci 8:17961803.

Kramer RH, Levitan ES, Wilson MP, Levitan IB (1988) Mechanism of calcium-dependent inactivation of a potassium current in Aplysia neuron R 15 : interaction between calcium and cyclic AMP. J Neurosci 8:1804-1813.

Livingstone MS (1985) Genetic dissection of Drosophila adenylate cyclase. Proc Natl Acad Sci USA 82:5992-5996.

Livingstone MS, Sziber PP, Quinn WG (1984) Loss of calcium/calmodulin responsiveness in adenylate cyclase of rutabaga, a Drosophila lcarning mutant. Cell 37:205-215.

Lynch TJ, Tallant EA, Cheung WY (1977) Rat brain adenylate cyclase. Further studies on its stimulation by a $\mathrm{Ca}^{2+}$-binding protein. Arch Biochem Biophys 182:124-133.

Lynch G, Larson J, Kelso S, Barrionuevo G, Schottler F (1983) Intracellular injections of EGTA block induction of hippocampal longterm potentiation. Nature 305:719-721.

MacDermott AB, Mayer ML, Westbrook GL, Smith SJ, Barker JL (1986) NMDA-receptor activation increases cytoplasmic calcium concentration in cultured spinal cord neurones [published erratum appears in Nature (1986) 321:888]. Nature 321:519-522.

MacDonald IA (1975) Differentiation of fluoride-stimulated and nonfluoride-stimulated components of beef brain cortex adenylate cyclase cy calcium ions, ethyleneglycol-bis-(beta-aminoethyl ether) N,N'-tetraacetic acid and Triton X-100. Biochim Biophys Acta 397:244-253.

Malenka RC, Kauer JA, Zucker RS, Nicoll RA (1988) Postsynaptic calcium is sufficient for potentiation of hippocampal synaptic transmission. Science 242:81-84.

Malnoe A, Stein EA, Cox JA (1983) Synergistic activation of bovine cerebellum adenylate cyclase by calmodulin and $\beta$-adrenergic agonists. Neurochem Int 5:65-72.

Nowak L, Bregestovski P, Ascher P, Herbet A, Prochiantz A (1984) Magnesium gates glutamate-activated channels in mouse central neurones. Nature 307:462-465.

Ocorr KA, Walters ET, Byrne JH (1983) Associative conditioning analog in Aplysia californica tail sensory neurons selectively increases cAMP content. Soc Neurosci Abstr 9:169.

Ocorr KA, Walters ET, Byrne JH (1985) Associative conditioning analog selectively increases cAMP levels of tail sensory neurons in Aplysia. Proc Natl Acad Sci USA 82:2548-2552.

Rescorla RA (1988) Behavioral studies of Pavlovian conditioning. Annu Rev Neurosci 11:329-352.

Rosenberg GB, Minocherhomjee AM, Storm DR (1987) Reconstitution of calmodulin-sensitive adenylate cyclase from bovine brain with phospholipids, calmodulin, and beta-adrenergic receptors. Meth ods Enzymol 139:776-791.

Ross EM, Howlett AC, Fergusson KM, Gilman AG (1978) Reconstitution of hormone sensitive adenylate cyclase activity with resolved components of the enzyme. J Biol Chem 253:6401-6412.

Salomon Y (1979) Adenylate cyclase assay. Adv Cyclic Nucleotide Res 10:35-55.

Salter RS, Krinks MH, Klee CB, Neer EJ (1981) Calmodulin activates the isolated catalytic unit of brain adenylate cyclase. $J$ Biol Chem 256:9830-9833.

Sano MS, Drummond GI (1981) Properties of detergent-dispersed adenylate cyclase from cerebral cortex. Presence of an inhibitor protein. J Neurochem 37:558-566.

Sastry BR, Goh JW, Auyeung A (1986) Associative induction of posttetanic and long-term potentiation in CA1 neurons of rat hippocampus. Science 232:988-990.

Schramm M, Selinger Z (1984) Message transmission: receptor controlled adenylate cyclase system. Science 225:1350-1356.

Seamon KB, Daly JW (1982) Guanine nucleotide dependence of calcium-calmodulin stimulation of adenylate cyclase in rat cerebral cortex and striatum. In: Calmodulin and intracellular calcium receptors. (Kakiuchi S, Hikada H, Means AR, eds). New York: Plenum.

Smigel MD (1986) Purification of the catalyst of adenylate cyclase. J Biol Chem 261:1976-1982.

Stent $G$ (1973) A physiological mechanism for Hebb's postulate of learning. Proc Natl Acad Sci USA 70:997-1001.

Treisman GJ, Bagley S, Gnegy ME (1983) Calmodulin-sensitive and calmodulin-insensitive components of adenylate cyclase activity in rat striatum have differential responsiveness to guanyl nuclcotides. J Neurochem 41:1398-1406.

Vogel SS, Chin GJ, Mumby SM, Schonberg M, Schwartz JH (1989) $G$ proteins in Aplysia: biochemical characterization and regional and subcellular distribution. Brain Res 478:281-292.

Volterra A, Sweatt JD, Siegelbaum SA (1987) Involvement of G proteins in the inhibitory action of FMRFamide through lipoxygenase metabolites of arachidonic acid in Aplysia sensory neurons. Soc Neurosci Abstr 13:1440.

Walters ET, Byrne JH (1983a) Associative conditioning of single sensory neurons suggests a cellular mechanism for learning. Science 219: $405-408$.

Walters ET, Byrne JH (1983b) Slow depolarization produced by associative conditioning of Aplysia sensory neurons may enhance $\mathrm{Ca}^{2+}$ entry. Brain Res 280:165-168.

Walters ET, Byrne JH, Carew TJ, Kandel ER (1983) Mechanoafferent neurons innervating tail of Aplysia. I. Response properties and synaptic connections. J Neurophysiol 50:1522-1542.

Westcott KR, La PD, Storm DR (1979) Resolution of adenylate cyclase sensitive and insensitive to $\mathrm{Ca}^{2+}$ and calcium-dependent regulatory protein (CDR) by CDR-sepharose affinity chromatography. Proc Natl Acad Sci USA 76:204-208.

Wigstrom H, Gustafsson B, Huang YY, Abraham WC (1986) Hippocampal long-term potentiation is induced by pairing single afferent volleys with intracellularly injected depolarizing current pulses. Acta Physiol Scand 126:317-319.

Yeager RE, Heideman W, Rosenberg GB, Storm DR (1985) Purification of the calmodulin-sensitive adenylate cyclase from bovine cerebral cortex. Biochemistry 24:3776-3783.

Yovell Y, Abrams TW (1988) Order dependence in the activation of adenylate cyclase by serotonin and $\mathrm{Ca}^{2+} /$ calmodulin: a possible molecular mechanism for associative learning in Aplysia. Soc Neurosci Abstr 14:910.

Yovell Y, Dudai Y (1987) The possible involvement of adenylate cyclase in learning and short-term memory: experimental data and some theoretical considerations. Isr J Med Sci 23:49-60.

Yovell Y, Dudai Y, Abrams TW (1986) Quantitative analysis of $\mathrm{Ca}^{2+} /$ calmodulin activated adenylate cyclase from Aplysia, Drosophila, and rat brain: possible relevance for associative learning. Soc Neurosci Abstr 12:400.

Yovell Y, Kandel ER, Dudai Y, Abrams TW (1987) Biochemical correlates of short-term sensitization in Aplysia: temporal analysis of adenylate cyclase stimulation in a perfused membranc preparation. Proc Natl Acad Sci USA 84:9285-9289. 